\title{
International Finance, Lévy Distributions, and the Econophysics of Exchange Rates
}

\author{
Sergio Da Silva ${ }^{\mathrm{a}, *}$, Raul Matsushita ${ }^{\mathrm{b}}$, Iram Gleria ${ }^{\mathrm{c}}$, Annibal Figueiredo ${ }^{\mathrm{d}}$ \\ Pushpa Rathie \\ ${ }^{a}$ Department of Economics, Federal University of Rio Grande Do Sul, 90040-000 Porto Alegre RS, \\ Brazil \\ ${ }^{\mathrm{b}, \mathrm{e}}$ Department of Statistics, University of Brasilia, 70910-900 Brasilia DF \\ ${ }^{\mathrm{c}}$ Department of Physics, Federal University of Alagoas, 57072-970 Maceio AL \\ ${ }^{\mathrm{d}}$ Department of Physics, University of Brasilia, 70910-900 Brasilia DF
}

\begin{abstract}
This paper surveys the developments in the field of international finance, in particular the research of economists on foreign exchange rates. That might be of interest to physicists working on the econophysics of exchange rates. We show how the econophysics agenda might follow naturally from the economists' research. We also present our own work on the econophysics of exchange rates.
\end{abstract}

PACS: 05.40.+j;02.50.-r

Keywords: Econophysics; Lévy distributions; Foreign exchange rates

\section{Introduction}

Economists working on the field of international finance traditionally felt uneasy with the ideas in modern finance theory, in particular with its notion of efficient markets. Instead, foreign exchange markets are widely believed to behave like the unstable and irrational asset markets described by Keynes [1].

The efficient markets assumption stands against the role of mass psychology. But that has been challenged recently by studies in behavioral finance. Since real returns are nearly unpredictable, the real price of stocks is believed by efficient market theorists to be close to their intrinsic value. However, behaviorists think that such a case for efficiency represents "one of the most remarkable errors in the history of economic thought" [2].

International finance has thus been in practice open economy macroeconomics. As it happens, macroeconomics seems to have failed as well to satisfactorily address exchange rate behavior, as this paper will show briefly. That circumstance makes international finance economists more prone to welcome the new ideas coming from physics. In socalled econophysics, the behavior of exchange rates and other financial assets are seen as complex. In complex systems with many interacting units, everything depends on everything else.

Section 2 discusses the role of expectations in macroeconomics. Section 3 focuses on the failure of modeling attempts in the framework of open economy macroeconomics. Section 4 shortly presents the econophysics agenda. Sections 5 and 6 introduce the Lévy

\footnotetext{
Corresponding author.

E-mail address: DrSergioDaSilva@hotmail.com (S. Da Silva).
} 
distributions and show some algebra behind them. Section 7 displays our previous results on the econophysics of exchange rates. Section 8 shows our work on exchange rate multiscaling. And section 9 concludes.

\section{Macroeconomics and expectations}

Macroeconomics was practically single-handed launched by Keynes [3]. Keynes' basic insight was that a market economy is inherently unstable, and that the source of instability lies in the logic of financial markets. According to Keynes, market capitalism should be neither left alone nor abolished, but stabilized. After the developments that took place in macroeconomics after Keynes, what still arguably survives of Keynesian economics today is the above insight [4].

Keynes' book was greatly simplified in a paper by Hicks [5] which proposed the socalled IS-LM model. For tractability, the IS-LM model assumed stationary expectations, i.e. people forecast no change for future prices. Stationary expectations is a reasonable assumption in a stable zero-inflation environment, but that is not so when inflation departures from nil.

Adaptive expectations came up to take the possibility of a non-zero inflation into account. Here people forecast by looking at previous inflation. Adaptive expectations is a fair assumption if prices are growing up at a constant rate. However, it is not if prices speed up. Even if prices accelerate at a constant rate, people with adaptive expectations will make systematic forecast errors.

So rational expectations is the assumption that people also consider an accelerating inflation together with all past and current information, including that of government policy. But rational expectations assumes, too, that people behave as if they have the "true model" of the economy in their minds, and that is too demanding.

One must seriously accept that the models used by real world people ("popular models") are not the rational expectations one [6]. Economic modeling has thus no choice but collecting data on the popular models themselves. By doing so, Shiller [6] and colleagues found feedback systems with complicated dynamics, where one does not need to refer to a trigger to explain a crash.

That rational expectations is a quite restrictive borderline case can be illustrated with reference to the El Farol bar problem put forward by Arthur [7, 8]. Suppose that one hundred people must decide independently each week whether to show up at their favorite bar (El Farol in Santa Fe). If someone predicts, say, that more than 60 will attend, he will avoid the crowds and stay home. If he predicts fewer than 60 he will go. No "correct" expectational model can be assumed to be common knowledge. If all use a model (say, rational expectations) that predicts few will go, all will go, invalidating the model. If all believe most will go, no one will go, invalidating the belief. Expectations will be forced to differ, i.e. expectations are necessarily heterogeneous.

Arthur and colleagues [9] extended the El Farol economy and generated out-ofequilibrium outcomes, of which the equilibrium with rational expectations is just a possible particular outcome. They found two possible regimes: (1) if parameters are set so that artificial agents update their hypotheses slowly, the diversity of expectations collapses quickly into the homogeneous rational expectations one; and (2) if the rate of updating of hypotheses is turned up, the artificial market displays several of the "anomalies" observed in real markets, such as unexpected price bubbles and crashes, random periods of high and 
low price variation, and the presence of technical trading.

These anomalies are thought of as out-of-equilibrium phenomena. It has to be said that mainstream macroeconomics and finance have also developed some equilibrium stories for such anomalies $[10,11]$. But although "rational expectation bubbles" might still be useful as a limiting case, from the above discussion it would not be sensible to assume rational expectations from the start.

That expectations should be both endogenous and heterogeneous is a lesson that international finance economists have already learned. They also have met complexity (an issue exhaustively discussed elsewhere [12]) in a book by Krugman [13]. Complexity may come to stay. A reason good enough for that to happen is the failure of modeling attempts in the framework of open economy macroeconomics. In what follows, that will be discussed in some detail.

\section{Open economy macroeconomics}

In the open economy macroeconomics field, nominal and real exchange rate volatility of the floating period following Bretton Woods was explained by "overshooting" in the Dornbusch [14] model. In such a benchmark model of the field, goods price stickiness is the critical reason for the exchange rate to overshoot its long run value in response to monetary shocks.

However, empirical evidence for overshooting is thin [15-17]. In particular, one empirical regularity inconsistent with it is the well documented $[15,18]$ tendency for spot and forward exchange rates to move in tandem.

Despite the fact that its empirical performance is not very successful [19], the Dornbusch model played a dominant role in shaping the literature on exchange rate dynamics through the early nineties [20]. That demonstrates "undeniable time-tested appeal of the traditional sticky price Keynesian model" [21]. Its prominence might also be related to the analytic simplicity of the model.

For macroeconomists, however, the Dornbusch model presents limitations related to its lack of microfoundations [22]. The quest for microeconomic foundations for macroeconomics is an almost consensus among macroeconomists, and is reminiscent of the so-called reductionism in physics. The research on microfoundations has begun when rational expectations stepped in. But reductionism is unlikely to be useful when complexity is involved [12]. So microfoundations are not the issue if macroeconomic phenomena are complex.

Traditional flexible price models of the exchange rate have been developed theoretically by the intertemporal approach to the current account [23-25]. A widely accepted standpoint by international macroeconomists is, however, that most important problems cannot be satisfactorily addressed in the framework of perfect price flexibility. That is another reason why empirical macroeconomists and policymakers have continued to use the Dornbusch model [15].

Overall it can be said that modeling with the standard macroeconomic models has failed empirically. Such a poor performance was made clear when studies demonstrated that a random walk predicts exchange rate behavior better than the models based on the "fundamentals" of the economy [26-28]. Also a number of empirical studies found that exchange rate data exhibit unit roots with a non-constant variance for the error term [2932]. Series are thus likely to be non-stationary with time dependent heteroskedasticity for 
the error.

To revive the standard macroeconomic models, Koedijk and Schotman [33] estimated an "error-correction" real exchange rate equation and showed that it is superior, in-sample, to a random walk. Also using dynamic error-correction techniques, Mark [34] considered an equation (derived from the Dornbusch model) to investigate the performance of the macro models concerning long run predictability. In forecasting tests over long horizons, piece of evidence was found that macro fundamentals help to predict the nominal exchange rate. The study by Chinn and Meese [35] also suggested that over long enough periods there is indeed a stationary relationship between the exchange rate and the fundamentals of the open macroeconomy models.

Despite that, the hypothesis that the exchange rate follows a random walk is still to be taken seriously. An interesting development that makes it possible to conciliate the apparent divergence between random walk and fundamentals is the model of De Grauwe and Dewachter [36], and De Grauwe, Dewachter, and Embrechts [37], where expectations are heterogeneous. De Grauwe and colleagues' model gives supplementary speculative dynamics to the Dornbusch model by considering chart rules concerning forecasting, and explains exchange rate movements by chaos. An advantage of chaotic models is to mimic the random walk pattern of the exchange rate with the "stochastic" behavior produced by deterministic solutions. The model of De Grauwe and associates has also been extended to show that massive foreign exchange intervention can remove the chaos [38].

In the mid 1980s the general sentiment was that the research had grown tired of searching for new macro models [39]. As a result, attention shifted from examination of macro models toward work related to the foreign exchange market as a financial market per se. Such a trend was reinforced by other studies pointing out that the nominal exchange rate shows much greater variability than the fundamentals [40-44]. Thus the literature on foreign exchange market microstructure focused on the behavior of agents and market characteristics rather than on the influence of macro fundamentals. One motivation for such work has been to understand the mechanisms generating deviations from fundamentals. A survey on that is provided by Flood [45], and another useful reference is Frankel, Galli, and Giovannini [46].

Other studies adopted the "news approach", which relies on the existence of unexpected shocks to explain exchange rate movements. It was shown however that only a small proportion of movements of the spot exchange rate is caused by news [47]. A survey of the papers dealing with news is provided by Frankel and Rose [48].

As an offshoot of the closed economy macro literature on real business cycles, the equilibrium exchange rate model [21, 49-53] came up to give a full account of the supply side. At this stage it is not possible to draw any firm conclusions concerning the empirical validity of the equilibrium model [19]. The emerging challenger of the equilibrium model is that of Obstfeld and Rogoff $[15,16]$. The studies collected together in Van Der Ploeg [54] allow a general appreciation of other new developments.

The model of the exchange rate developed by Obstfeld and Rogoff (the "redux" model) assumes monopolistic competition and sticky nominal prices in the short run. While preserving the sticky price feature of the Dornbusch model, it provides a more rigorous framework than the latter by incorporating the intertemporal approach to the current account. That allows for evaluating the welfare effects of macro policies on output and the exchange rate, a possibility not contemplated by the flexible price intertemporal approach. 
The results of Obstfeld and Rogoff sometimes differ sharply from those of either the Dornbusch model or the flexible price intertemporal approach to the current account. If the redux model succeed empirically, macroeconomists might claim that lack of microfoundations partly explains the bad empirical performance of the Dornbusch model. The wave of research initiated by the redux model is sometimes labelled "new open economy macroeconomics". Lane [55] and Sarno [56] present surveys. (The speculative dynamics side of the model of De Grauwe and colleagues has also been blended with the model of Obstfeld and Rogoff to produce a chaotic nominal exchange rate [57]).

Lane questions the relevance of this literature for policymaking because many welfare results are highly sensitive to the precise denomination of price stickiness and the specification of preferences. But the widespread commitment with microfoundations and the many unanswered questions that remain should ensure that the literature is likely to grow yet further in the coming years among macroeconomists.

Where do we then stand in the open economy macroeconomics literature? The Dornbusch model demonstrates undeniable time-tested appeal. But the redux model comes up to update the Dornbusch model as regards microfoundations and a supposed breakthrough is to allow an explicit welfare analysis as far as policy is concerned. The welfare results of the new open economy macroeconomics literature are highly sensitive to the precise denomination of price stickiness and the specification of preferences, though. For that reason, the literature is of only limited interest in policy circles. Notwithstanding, the lack of welfare criteria of the Dornbusch model is claimed to yield misleading policy prescriptions; and that will encourage macroeconomists to further research on the new open economy macroeconomics.

\section{The econophysics agenda}

Unlike mainstream economists, physicists usually think of the macroeconomy as a complex system, with many interacting subunits, where everything depends on everything else. But how does everything depend on everything else? Here physicists are looking for empirical laws that will describe this complex interaction [58]. So they have decided to examine empirical economic and financial facts prior to the building up of models.

By adapting the biased random walk of Bachelier [59] for the S\&P500 data (which encompass the crash of 19 October 1987), Stanley and colleagues [58] show that the huge drop of Black Monday is virtually impossible in the model. The biased random walk has a probability density function that is Gaussian. With returns (fluctuations) normalized to one standard deviation, the probability of having more than 5 standard deviations is essentially zero. However, there are 30 or 40 shocks in the S\&P500 returns that exceed 5 standard deviations. And Black Monday is more than 34 standard deviations [58]. Research on econophysics that take empirical data into account aims at showing that catastrophic, rare events like Black Monday must be considered as part of the overall picture; they are not (in a sense) "anomalies". Even the great stock market crashes would be simply ordinary (although infrequent) events.

As observed [58], almost everything in nature, including disordered things, has scale. Most functions in physics have a characteristic scale and almost all physics comes down to solving a differential equation. But some systems in nature lack a scale. In particular, systems with many interacting units (like the macroeconomy) generally exhibit scale invariance that can be expressed by power laws. This is the case of financial price 
fluctuations as well, like those of the S\&P500 [60, 61].

Mandelbrot [62] looked at how random changes in cotton prices were distributed by size and did not find a bell curve. Instead, he discovered that price changes do not have a typical size, thereby being governed by a non-Gaussian power law. That allows one to see large fluctuations in market prices as a result of the natural, internal workings of markets; they can strike from time to time even if there are no sudden alterations of the fundamentals. Mandelbrot suggested a stable Lévy distribution [63] to model the cotton prices. Indeed Mandelbrot [64] showed how Lévy distributions can be applied to a number of situations and coined the term "Lévy flights".

Financial asset prices are also unlikely to follow Gaussian distributions [65]. Skyhigh peaks and fat tails are pervasive in financial data. Although leptokurtosis could be accounted for by stable Lévy distributions, these have never been established in mainstream finance. One reason is related to their property of infinite variance. Since volatility is a central concept to finance, it is useful for the variance to be finite. (The debate in the early days of modern finance can be appreciated in Cootner [66]).

To remedy such a deficiency, a truncated Lévy distribution has been put forward $[67,68]$. A truncated Lévy flight aims at modeling financial series through a non-stable distribution which features non-normal scaling power laws and finite variance. The truncated Lévy flight is then a candidate to satisfactorily model financial data. Indeed, that has been shown for the S\&P500 [68] and other stock markets [69-71], as well as foreign exchange rates [72]. (An earlier study that found power laws in foreign exchange markets is that of Müller et al. [73].)

Non-Gaussian power laws are expected to coexist uneasily with mainstream finance theory, which is built on the efficient market hypothesis. However, econophysics does not clash with mainstream finance. Overall physicists see the efficient market as an idealized system and real markets as only approximately efficient. They think the concept of efficient markets is still useful to model financial markets. But rather than simply assuming normality from the start, they try to fully characterize the statistical properties of the random processes observed in financial markets [74].

\section{Lévy distributions}

The sum of independent random variables is distributed like anyone of them. Lévy [75] investigated the uniqueness of the Gaussian distribution in displaying such a property, which follows from the law of large numbers. He put forward a more general approach valid for distributions with an infinite second moment.

Let $P(x)$ be a distribution of a random variable $x$ which is normalized to

$$
\int_{\infty}^{\infty} P(x) \mathrm{d} x=1
$$

whose characteristic function is

$$
\varphi(q)=\int_{-\infty}^{\infty} \mathrm{d} x \mathrm{e}^{\mathrm{i} q x} P(x)
$$

A linear combination

$c x_{3}=c_{1} x_{1}+c_{2} x_{2}$

for $x_{1} \neq x_{2}$ is stable if $x_{1}, x_{2}, x_{3}$ are governed by the same $P\left(x_{j}\right)$. The Gaussian 
distribution

$$
P_{G}(x)=\left(2 \pi \sigma_{d}\right)^{-1 / 2} \exp \left(-\frac{x^{2}}{2 \sigma_{d}}\right)
$$

gives precisely an example of a stable distribution with second moment which is finite $\sigma_{d}=<x^{2}>$

Lévy [75] found a distinct class of solutions. To see this let us use Eq. (3) to write

$P\left(x_{3}\right) \mathrm{d} x_{3}=P\left(x_{1}\right) P\left(x_{2}\right) \delta\left(x_{3}-\frac{c_{1}}{c} x_{1}-\frac{c_{2}}{c} x_{2}\right) \mathrm{d} x_{1} \mathrm{~d} x_{2}$

By considering Eq. (2), the characteristic function is

$\varphi(c q)=\varphi\left(c_{1} q\right) \varphi\left(c_{2} q\right)$

which in $\operatorname{logs}$ is given by

$\ln \varphi(c q)=\ln \varphi\left(c_{1} q\right)+\ln \varphi\left(c_{2} q\right)$

Its solution is

$\ln \varphi_{\alpha}(c q)=(c q)^{\alpha}=c \mathrm{e}^{-\mathrm{i} \alpha|q|}|q|^{\alpha}$

for an arbitrary parameter $\alpha$ and

$\left(\frac{c_{1}}{c}\right)^{\alpha}+\left(\frac{c_{2}}{c}\right)^{\alpha}=1$

Distribution $P_{\alpha}(x)$ with characteristic function

$\varphi_{\alpha}(q)=\exp \left(-c|q|^{\alpha}\right)$

is the Lévy distribution of index $\alpha$. Condition $0<\alpha \leq 2$ guarantees that

$P_{\alpha}(x)=\int \mathrm{d} q \mathrm{e}^{\mathrm{i} q x} \varphi_{\alpha}(q)$

is positive. If $\alpha=2$ the Lévy collapses to the Gaussian $P_{G}(x)$. If $\alpha=1$ the Lévy becomes a Cauchy distribution

$P_{1}(x)=\frac{c}{\pi} \frac{1}{x^{2}+c^{2}}$

Also, for $|x| \rightarrow \infty$ we have

$P_{\alpha}(x) \approx \frac{1}{\pi} \alpha c \Gamma(\alpha) \sin \frac{\pi \alpha}{2} \frac{1}{|x|^{\alpha+1}}$

A Lévy process is a time-dependent process that at an infinitesimal time has the Lévy distribution of the process variable. The characteristic function of the Lévy process is $\varphi_{\alpha}(q, t)=\exp \left(-c t|q|^{\alpha}\right)$

and the original Lévy process is given by its inverse Fourier transform, i.e.

$P_{\alpha}(x, t)=\int \mathrm{d} q \mathrm{e}^{\mathrm{i} q x-c t|q|^{\alpha}}$

For $|x| \rightarrow \infty$ an equation similar to (14) holds. From this equation, moment of order $m$ is

$<|x|^{m}>=\infty, m \geq \alpha$

where $m$ need not be integer. Second moment $(m=2)$ is infinite since $\alpha<2$. More details on the Lévy process (and also on so-called Lévy walks) can be found elsewhere [76]. 
As observed, a sharply truncated Lévy flight (TLF) has been put forward. But it is still possible to define a TLF with a smooth cutoff that yields an infinitely divisible characteristic function [77]. In a smoothly truncated Lévy flight (STLF), the cutoff is carried out by asymptotic approximation of a stable distribution valid for large values [78].

Yet the STLF breaks down in the presence of positive feedbacks [79, 80]. But the cutoff can still be alternatively combined with a statistical distribution factor to generate a gradually truncated Lévy flight (GTLF) [79, 80]. Nevertheless that procedure also brings fatter tails. The GTLF itself also breaks down if the positive feedbacks are strong enough. That apparently happens because the truncation function decreases exponentially.

We have ourselves put forward what we call an exponentially damped Lévy flight (EDLF) [81], in which the gradually truncated Lévy is modified and then combined with the smoothly truncated one. In the presence of increasing and positive feedbacks, our distribution smoothly and gradually deviates from the Lévy. The truncation parameters are estimated by nonlinear least squares to provide an optimized fit for the tails. Our EDLF seems to fairly fit data on daily exchange rates. Section 7 will discuss that in some detail.

Whether scaling is single or multiple depends on how a Lévy flight is broken. While the abruptly truncated Lévy flight (the TLF itself) exhibits mere single scaling, the STLF shows multiscaling [78, 82]. When employing the abruptly TLF [74] to fit the exchange rate data we have realized that such data set might be fitted by an EDLF as well [81]. That is interesting because we can focus on the exchange-rate multiscaling properties stemming from the EDLF. Not surprisingly, and in accordance with previous literature [83-88], we find multiscaling to be pervasive among exchange rates. This will be shown in section 8 .

\section{More algebra behind the Lévy distributions}

$X_{t}$,

Now let $S_{n}$ be the sum of $n$ independent and identically distributed random variables

$S_{n}=X_{1}+X_{2}+X_{3} \ldots+X_{n}$

with $\mathrm{E}\left(X_{t}\right)=0$. It is usual to work with returns in finance, i.e.

$Z_{\Delta t}(t)=S_{t}-S_{t-\Delta t}=X_{t}+X_{t-1}+\ldots+X_{t-\Delta t+1}$

where $\Delta t$ is a time lag. Now consider the symmetric Lévy distribution

$L\left(Z_{\Delta t}\right) \equiv \frac{1}{\pi} \int_{0}^{\infty} \exp \left(-\gamma \Delta t q^{\alpha}\right) \cos \left(q Z_{\Delta t}\right) \mathrm{d} q$

where $0<\alpha<2$, and $\gamma>0$ is a scale factor.

The characteristic function of $(20), \varphi(K)$, is such that

$\ln [\varphi(K)]=-\gamma \Delta t|K|^{\alpha}$

which satisfies $\Delta t \ln [\varphi(K)]=\ln \left[\varphi\left(\Delta t^{1 / \alpha} K\right)\right]$. That means that the corresponding probability distribution is

$L\left(\mathrm{Z}_{\Delta t}\right)=\Delta t^{-1 / \alpha} L\left(\Delta t^{-1 / \alpha} \mathrm{Z}_{\Delta t}\right)=\Delta t^{-1 / \alpha} L\left(Z_{s}\right)$

where $Z_{s}=\Delta t^{-1 / \alpha} Z_{\Delta t}$ is a scaled variable at $\Delta t$.

Let us define a modified Lévy flight (MLF) through

$\mathrm{P}\left(Z_{\Delta t}\right)=\eta L\left(Z_{\Delta t}\right) f\left(Z_{\Delta t}\right)$

where $\eta$ is a normalizing constant, and $f\left(Z_{\Delta t}\right)$ is the change carried out on the distribution.

The abruptly truncated Lévy flight (TLF) is an extension to which 
$f\left(Z_{\Delta t}\right)=f_{\text {abrupt }}\left(Z_{\Delta t}\right)= \begin{cases}0, & \left(\left|Z_{\Delta t}\right|>l_{\max }\right) \\ 1, & \left(\left|Z_{\Delta t}\right| \leq l_{\text {max }}\right)\end{cases}$

where $l_{\max }$ is the step size at which the distribution begins to departure from the ordinary Lévy. The TLF is not stable and has finite variance, thereby converging to a Gaussian equilibrium according the central limit theorem. The characteristic function of the TLF is no longer infinitely divisible. Nevertheless approximate scaling can still occur for a finite time interval [74]. But scaling must break down for longer time intervals.

Now consider the STLF $[77,78]$. The cutoff parameter $\lambda_{0}>0$ is introduced into Eq. (6) as

$f\left(Z_{\Delta t}\right)=f_{\text {smooth }}\left(Z_{\Delta t}\right)= \begin{cases}C a\left|Z_{\Delta t}\right|^{-1-\alpha} e^{-\lambda_{0}\left|Z_{\Delta t}\right|}, & \left(Z_{\Delta t}<0\right) \\ C b Z_{\Delta t}^{-1-\alpha} e^{-\lambda_{0} Z_{\Delta t}}, & \left(Z_{\Delta t}>0\right)\end{cases}$

Function $f_{\text {smooth }}\left(Z_{\Delta t}\right)$ is based on the asymptotic approximation of a stable distribution of index $\alpha$ valid for large values of $\left|Z_{\Delta t}\right|$ when $\gamma=1$. It exhibits a power law behavior. For $0<$ $\alpha<1$, the first term of the expansion of $L\left(Z_{\Delta t}\right)$ can be approximated by

$L\left(Z_{\Delta t}\right) \approx \frac{\gamma \Delta t \Gamma(1+\alpha) \sin (\pi \alpha / 2)\left|Z_{\Delta t}\right|^{-(1+\alpha)}}{\pi}$

By taking into account the particular case of the Lévy where $a=b$, we get

$\ln \left[\varphi_{\text {STLF }}(K)\right]= \begin{cases}\gamma\left\{\left(\lambda_{0}^{2}+K^{2}\right)^{\alpha / 2} \cos (\alpha \theta)-\lambda_{0}^{\alpha}\right\}, & (0<\alpha<1) \\ \gamma \lambda_{0}^{\alpha}\left\{\left(1+i K / \lambda_{0}\right)^{\alpha}-1\right\}, & (1<\alpha<2)\end{cases}$

where $\theta=\arctan \left(K / \lambda_{0}\right)$, and $\gamma=C \Gamma(-\alpha)$. Now the characteristic function ends up infinitely divisible.

The GTLF $[79,80]$ is defined as

$f\left(Z_{\Delta t}\right)=f_{\text {gradual }}\left(Z_{\Delta t}\right)=\left\{\exp \left\{-\left(\frac{\left|Z_{\Delta t}\right|-l_{c}}{\beta_{1}}\right)^{\beta_{0}}\right\}, \quad\left(\begin{array}{ll}\left(\left|Z_{\Delta t}\right| \leq l_{c}\right) \\ \end{array}\right.\right.$

where $l_{c}$ is the step size at which the distribution starts to deviate from the Lévy. Here $\beta_{0}$ and $\beta_{1}$ are the constants related to the truncation.

When using the currency data to be presented in section 7 , we have realized that their distributions deviate from the Lévy in a smooth and gradual fashion after $\left|Z_{\Delta t}\right|>l_{c}$. Sometimes the deviations were also caught increasing. Such a class of deviations was already found to be positive [79, 80], which means even fatter tails. It has been argued [79, 80] that, since the physical capacity of a system is limited, the feedback begins to decrease exponentially (and not abruptly) after a certain critical step size. In contrast, in the presence of our previously found increasing deviations, we think that an abrupt truncation is necessary still. In such cases, using the truncation approaches as in Eqs. (24), (25), and (28) might prove not to be appropriate.

For that very reason we have suggested [81] the broader formulation for $f\left(Z_{\Delta t}\right)$ dubbed EDLF. The EDLF encompasses the previous TLF, STLF, and GTLF. Our EDLF is defined as 
$f\left(Z_{\Delta t}\right)=f_{\text {damped }}\left(Z_{\Delta t}\right)= \begin{cases}1, & \left|Z_{\Delta t}\right|<l_{c} \\ \left(\Delta t^{-1 / \alpha}\left|Z_{\Delta t}\right|+\vartheta\right)^{\tau_{1}} \exp \left\{H\left(Z_{\Delta t}\right)\right\}, & \left(l_{c}<\left|Z_{\Delta t}\right|<l_{\max }\right) \\ 0, & \left|Z_{\Delta t}\right|>l_{\max }\end{cases}$

where

$H\left(Z_{\Delta t}\right)=\lambda_{1}+\lambda_{2}\left[1-\left|Z_{\Delta t}\right| / l_{\max }\right]^{\tau_{2}}+\lambda_{3}\left(\left|Z_{\Delta t}\right|-l_{c}\right)^{\tau_{3}}$

and $\vartheta, \lambda_{1}, \lambda_{2} \leq 0, \lambda_{3} \leq 0, \tau_{1}, \tau_{2}$, and $\tau_{3}$ are parameters describing the deviations from the Lévy, $l_{c}$ is (as before) the step size at which the distribution begins to deviate from the Lévy, and $l_{\max }$ is the step size at which an abrupt truncation is carried out.

Note that when $l_{\max } \rightarrow \infty$, we have

$H\left(Z_{\Delta t}\right)=\lambda_{1}+\lambda_{2}+\lambda_{3}\left(\left|Z_{\Delta t}\right|-l_{c}\right)^{\tau_{3}}$

By setting $\vartheta=0, \tau_{1}=-1-\alpha, l_{c}=0$, and $\tau_{3}=1$ in Eqs. (29), (30), and (31), the resulting function is thus equivalent to the smooth case given by Eq. (25). When $l_{\max } \rightarrow \infty$, the similar function for the gradual case can be found by setting $\vartheta=\lambda_{1}=\lambda_{2}=\tau_{1}=0$. The abrupt case is given by setting $l_{c}=0$ and choosing the appropriate parameters such that $H\left(Z_{\Delta t}\right) \rightarrow-\infty$.

\section{Illustration with exchange rate data}

Now we turn to review our own work on the dollar prices of 30 currencies plus a fake euro. The data sets for the 30 currencies were taken from the Federal Reserve website. As standard, here we ignore "holes" from weekends and holidays; analysis thus concentrates on trading days. Since the series for the real euro is too short, we have decided to take a false euro instead in order to get a longer series. We build the fictitious series for the euro by following a methodology put forward by Ausloos and Ivanova [89]. Table 1 shows the 31 currencies, historical time period, and number of data points.

Fig. 1 displays the logarithm of the probability density functions (PDFs) of currency returns for selected countries in Table 1, namely Australia, Britain, Canada, Belgium, India, Brazil, China, and South Africa. Increases in time horizons range from $\Delta t=1,2$, and 5 trading days (a week) to 240 trading days (a year). A spreading of the PDFs characteristic of any random walk is observed. Fig. 2 shows a log-log plot of the "probability of return to the origin" $P(0)$ against $\Delta t$ [68]. Roughly, scaling power laws emerge for the currencies within the time window of $1 \leq \Delta t \leq 100$; and that fact is at first consistent with the presence of a TLF.

Table 2 presents parameters $\alpha$ and $\gamma$ for the currencies in Table 1. Parameter $\alpha$ is greater than two for six countries, namely Canada, China, Malaysia, South Africa, Thailand, and Venezuela; the currencies of these countries may (or may not) be outside the Lévy regime. For all the other currencies, a TLF might describe the data within a time window of (generally) 100 trading days (not shown).

Thus a Lévy PDF could model the modal region of such processes within a finite time interval. Thus we have made a case for the presence of such TLFs (with finite second moments) to be pervasive in daily time series of currency returns.

We have also moved up to assess how our EDLF adjusts to the same data. But here estimation of parameters $\alpha$ and $\gamma$ departures from our previous approach, which is standard in this type of literature. Such parameters are usually estimated by plotting the probability of return to the origin against $\Delta t$. Our new hybrid estimation process takes a maximum 
likelihood approach for $\alpha$ and $\gamma$, and nonlinear least squares for the other parameters.

From Eq. (23), the log likelihood function is given by

$\sum_{z} \ln \left(\mathrm{P}\left(z_{\Delta t}\right)\right)=\sum_{z} \ln \left(\mathrm{L}\left(z_{\Delta t}\right)\right)+\sum_{z} \ln \left(f\left(z_{\Delta t}\right)\right)+$ constant.

The maximum likelihood estimates are obtained by minimizing Eq. (32) as a function of the distribution parameters. Note that (32) is composed of three parts. For $\Delta t=$ 1 , the first part depends only on $\alpha$ and $\gamma$, and the second one depends on the other parameters. As a result, the estimation process can be carried out separately for $\Delta t=1$. The maximum likelihood estimates of $\alpha$ and $\gamma$ are the same as those obtained if the process were a Lévy. Such a practice is discussed elsewhere [90, 91], and a computer program for implementing it (called Stable.exe) is available online at http://academic2.american.edu/ jpnolan/.

With $\hat{\alpha}$ and $\hat{\gamma}$ being the maximum likelihood estimates of $\alpha$ and $\gamma$, let $\hat{P}\left(z_{s}\right)$ be the sample probabilities of the scaled variable at $\Delta t$, i.e. $z_{s}=\Delta t^{-1 / \hat{\alpha}} z_{\Delta t}=\Delta t^{-1 / \alpha} Z_{\Delta t}$. Also let $\hat{L}\left(z_{1}\right)$ be the Lévy distribution using $\hat{\alpha}, \hat{\gamma}$ for $\Delta t=1$. The difference $\ln \hat{P}\left(z_{s}\right)-\ln \hat{L}\left(z_{1}\right)$ shows how data deviate from the original Lévy process. Assuming that $\ln \hat{P}\left(z_{s}\right)-\ln \hat{L}\left(z_{1}\right)=\ln f_{\text {damped }}\left(z_{\Delta t}\right)$, which equals

$\beta_{1} \ln \left(\left|z_{s}\right|+\vartheta\right)+H\left(z_{s}\right), \quad\left(\Delta t^{-1 / \alpha} l_{c}<\left|z_{s}\right|<\Delta t^{-1 / \alpha} l_{\max }\right)$,

then the parameters describing the deviations from the Lévy can be estimated by a nonlinear least squares procedure. Results are displayed in Table 3.

The sample probabilities of a scaled variable at $\Delta t, \hat{P}\left(z_{s}\right)$ together with a Lévy distribution using $\hat{\alpha}$ and $\hat{\gamma}$ were then calculated. The differences $\ln \hat{P}\left(z_{s}\right)-\ln \hat{L}\left(z_{1}\right)$ are shown in Fig. 4. The resulting curves are shown as the continuous lines in Fig. 4. Their parameter estimates obtained by the nonlinear least squares method are also presented in Table 3. In all cases, parameters $\lambda_{3}$ and $\beta_{3}$ were dropped from the model. Here zero estimates for $\lambda_{3}$ and $\beta_{3}$ mean that the scaled PDFs exhibit heavy tails with increasing and positive feedbacks.

The examples in Fig. 5 show that our EDLF fits the exchange rate data reasonable well. Note that the larger dispersion at the tails area in Fig. 5 is partly due to the equal hystogram bins taken in the scale of $Z$. The dispersion could be significantly reduced if we had taken a $\ln Z$ axis with equal bins in $\ln Z$ [76]. It is also worth emphasizing that the data in Fig. 4 show $\log$ differences $\ln \hat{P}\left(z_{s}\right)-\ln \hat{L}\left(z_{1}\right)$ that are increasing. And that is why fatter tails with increasing (instead of decreasing) and positive feedback emerge.

\section{Multiscaling}

Our suggested EDLF has been employed to study the multiscaling properties of the exchange rates above [92]. Here we briefly discuss our contribution on this subject. (A discussion of multiscaling together with comprehensive references is given elsewhere [76].)

By scaling $Z_{\Delta t}$ together with the truncation parameters, a distribution can be collapsed onto $\Delta t=1$. We thus have

$\mathrm{P}\left(Z_{\Delta t}\right)=\eta L\left(Z_{\Delta t}\right) f\left(Z_{\Delta t}\right)=\Delta t^{-1 / \alpha} \eta L\left(Z_{s}\right) f_{s}\left(Z_{s}\right)=\Delta t^{-1 / \alpha} \mathrm{P}_{\mathrm{s}}\left(Z_{s}\right)$ 
where $Z_{s}=\Delta t^{-1 / \alpha} Z_{\Delta t}$, and $f_{s}\left(Z_{s}\right)$ is a truncation function defined by the scaled parameters $l_{m s}=\Delta t^{-1 / \alpha} l_{\max }, l_{c s}=\Delta t^{-1 / \alpha} l_{c}$, and $\lambda_{3 s}=\Delta t^{\tau_{3} / \alpha} \lambda_{3}$.

Power laws for both the $K^{\text {th }}$ absolute moment and norm of the characteristic function of the EDLF can be derived as follows. By scaling $Z_{\Delta t}$ and using $l_{m s}=\Delta t^{-1 / \alpha} l_{\max }$, $l_{c s}=\Delta t^{-1 / \alpha} l_{c}$, and $\lambda_{3 s}=\Delta t^{\tau_{3} / \alpha} \lambda_{3}$, the $K^{t h}$ absolute moment $E\left[\left|Z_{\Delta t}\right|^{K}\right]$ can be reckoned as $E\left[\left|Z_{\Delta t}\right|^{K}\right]=\Delta t^{K / \alpha} E_{s}\left[\left|Z_{s}\right|^{K}\right]$

Note that such a power law depends on $\alpha$ and $l_{\max }, l_{\mathrm{c}}$, and $\lambda_{3}$. If it were dependent only on $\alpha$, multiscaling could not emerge because $\ln E\left[\left|Z_{\Delta t}\right|^{K}\right]$ would be given by a linear function $K / \alpha$.

$$
\begin{aligned}
& \quad \text { Now let } \\
& <\left|Z_{\Delta t}(t)\right|^{\mathrm{K}}>=\frac{1}{n} \sum_{t=1}^{n}\left|S_{t}-S_{t-\Delta t}\right|^{K} \\
& \text { and } \\
& <|\widetilde{Z}|^{\mathrm{K}}>=\frac{1}{n} \sum_{t=1}^{n}\left|S_{t}-S_{t-1}\right|^{K}
\end{aligned}
$$

be the $K^{\text {th }}$ sample mean of the lagged absolute values of $S_{t}$ at the time interval $\Delta t$ and 1 respectively. For moments which are low enough (such as $0<K<\alpha), \mathrm{P}\left(Z_{\Delta t}\right)$ is expected to be approximated by $L\left(Z_{\Delta t}\right)$, which in turn does not depend on the truncation parameters [78]. The reason why that might occur is that tails differ, and thereby they do not contribute a great deal to the low moment case [78]. Thus we expect $\left\langle\left|Z_{\Delta t}\right|^{K_{>}} \approx \Delta t^{K / \alpha}\right.$ $<|\widetilde{Z}|^{K}>$ to hold for lower moments. That means that the ratio $R(K, \Delta t)=<\left|S_{\Delta t}\right|^{K}>\left.|<| \widetilde{S}\right|^{K}>$ scales with $\Delta t$ as $R(K, \Delta t)=\Delta t^{K / \alpha}$.

By considering the case with $K>\alpha, l_{\max }$ finite, $\vartheta=0$, and $\lambda_{3}=0$, it can be shown [92] that

$$
E\left[\left|Z_{\Delta t}\right|^{K}\right] \approx \frac{\Delta t^{K / \alpha} 2 \eta \gamma \Gamma(1+\alpha) \sin (\pi \alpha / 2)}{\pi} O_{\text {damped }}
$$

where

$$
O_{\text {damped }}=\frac{l_{c s}^{(K-\alpha)}}{K-\alpha}+l_{m s}^{K-\alpha+\tau_{1}} e^{\lambda_{1}} \sum_{j \geq 0} \frac{\lambda_{2}^{j}}{j !} B_{u}\left(1+j \tau_{2}, K-\alpha+\tau_{1}\right)
$$

and $l_{m s}=\Delta t^{-1 / \alpha} l_{\max }, l_{c s}=\Delta t^{-1 / \alpha} l_{c}$, and $B_{u}\left(1+j \tau_{2}, K-\alpha+\tau_{1}\right)$ is the incomplete Beta function with $1+j \tau_{2}>0, K-\alpha+\tau_{1}>0$, and $u=1-l_{c} / l_{\max }$. Thus the ratio $E\left[\left|Z_{\Delta t}\right|^{K}\right] / E\left[\left|Z_{1}\right|^{K}\right]$ is approximately given by

$$
\Delta t^{K / \alpha} \frac{l_{c s}{ }^{K-\alpha}+(K-\alpha) l_{m s}^{K-\alpha+\tau_{1}} e^{\lambda_{1}} \sum_{j \geq 0} \frac{\lambda_{2}^{j}}{j !} B_{d}\left(1+j \tau_{2}, K-\alpha+\tau_{1}\right)}{l_{c}^{(K-\alpha)}+(K-\alpha) l_{\max }^{K-\alpha+\tau_{1}} e^{\lambda_{1}} \sum_{j \geq 0} \frac{\lambda_{2}^{j}}{j !} B_{d}\left(1+j \tau_{2}, K-\alpha+\tau_{1}\right)}
$$

In such a situation, the ratio $R(K, \Delta t)$ scales as $R(K, \Delta t)=\Delta t^{K / \alpha}$ if the ratio of (40) equals one. Nakao [78] previously noted that the self-similarity of $E_{s}\left[\left|Z_{s}\right|^{K}\right]$ breaks down if $K>\alpha$. If $K<\alpha$ then $E_{s}\left[\left|Z_{s}\right|^{K}\right] \approx E\left[\left|Z_{1}\right|^{K}\right]$; otherwise, $E_{s}\left[\left|Z_{s}\right|^{K}\right] \neq E\left[\left|Z_{1}\right|^{K}\right]$. In 
practice the power law is of type $R(K, \Delta t)=v \Delta t^{K / \alpha}$ for some time interval $\Delta t$, where $v$ is a constant describing quasi-stable processes [72]. In such situations, ratio (40) gets approximately equal to $v$ for $\Delta t_{1} \leq \Delta t \leq \Delta t_{2}$. By depending solely on how the truncation parameters are set, a number of distinct scaling patterns can be uncovered. For example, if $l_{c}=0$ then $E\left[\left|Z_{\Delta t}\right|^{K}\right] / E\left[\left|Z_{1}\right|^{K}\right] \approx \Delta t^{1-\tau_{1} / \alpha}$.

The norm of the characteristic function can also be used to assess parameter $\gamma$ by taking into account the same assumption that $P\left(Z_{\Delta t}\right) \approx L\left(Z_{\Delta t}\right)$ for low values of $|K|$. Since $\varphi(K) \equiv \mathrm{E}\left[e^{i K Z_{\Delta t}}\right]=\mathrm{E}\left[\cos \left(K Z_{\Delta t}\right)+i \sin \left(K Z_{\Delta t}\right)\right]=\mathrm{E}\left[\cos \left(K Z_{\Delta t}\right)\right]+i \mathrm{E}\left[\sin \left(K Z_{\Delta t}\right)\right]$ then the squared norm of $\varphi(K)$ is $\|\varphi(K)\|^{2}=\mathrm{E}^{2}\left[\cos \left(K Z_{\Delta t}\right)\right]+\mathrm{E}^{2}\left[\sin \left(K Z_{\Delta t}\right)\right]$. For some $K$ and $\Delta t,\|\varphi(K)\|$ can be estimated by

$\|\hat{\varphi}(K)\|^{2}=<\cos \left(K Z_{\Delta t}\right)>^{2}+<\sin \left(K Z_{\Delta t}\right)>^{2}$

By assuming that $\ln [\varphi(K)] \approx-\gamma \Delta t|K|^{\alpha}$ for $0<K<\alpha$, the "estimated" norm in logs of the characteristic function is $\ln \|\varphi(K)\|$, and then we can expect that $\ln \|\hat{\varphi}(K)\|=-\gamma \Delta t|K|^{\alpha}$.

Fig. 6 displays sample ratios $R(K, \Delta t)$ for several values of $K$ in log-log plots of the exchange rates. Some ratios exhibit power law dependence on $\Delta t$. Pictures with lines which are dependent on $K$ emerge in some of the plots.

By fitting $\ln R(K, \Delta t)=\xi \ln \Delta t$ for every $K$, we get the corresponding scaling exponents shown in Fig. 7. Some curves show linear dependence on $K$, for $0<K<\alpha$. However scaling breaks down after $K>\alpha$, and a nonlinear behavior steps in.

Fig. 8 displays the sample logarithm of the absolute characteristic function versus $\Delta t$ for several values of $K$. A power law dependence on $\Delta t$ seems again to emerge from the pictures.

By fitting $\ln \|\hat{\varphi}(K)\|=\zeta \Delta t$ for every $K$, the estimated values of $\zeta$ versus $|K|^{\hat{\alpha}}$ are plotted in Fig. 9. Britain, Brazil and Canada show a linear dependence for all $K<3$. For all the other cases, the linear dependence on the initial values of $K$ are followed by nonlinear patterns.

Table 4 shows results for all the currencies, where either single scaling or multiscaling is displayed in connection with both $(\xi$ and $\zeta)$ exponents. As can be seen, multiscaling is pervasive among foreign exchange rates.

\section{Conclusion}

This paper is a survey of the work of economists in the field of exchange rates called international finance. It is also a presentation of our own previous work on the econophysics of exchange rates. That might be of interest to physicists working on the general subject of econophysics.

Overall the paper is intended to show how the econophysics agenda might follow naturally from the economists' research as far as international finance is concerned. Our own work on the subject focuses mainly on the Lévy distribution and its applications to exchange rate data. Among other things, we present our suggested method to break the Lévy tails and show the multiscaling properties of actual exchange rates in connection with our exponentially damped Lévy flight. 


\section{Acknowledgements}

We are grateful to Aline De Almeida, Aline Gandon, and Martha Scherer for research assistance. 
Table 1

Description of data sets.

\begin{tabular}{|c|c|c|c|}
\hline Country & Currency & Time Period & Data Points \\
\hline Australia & Australian Dollar & 4Jan71 - 10Jan03 & 8025 \\
\hline Austria & Shilling & 4Jan71 - 31Dec98 & 6999 \\
\hline Belgium & Belgian Franc & 4Jan71 - 31Dec98 & 7013 \\
\hline Brazil & Real & 2Jan95 - 10Jan03 & 2014 \\
\hline Britain & Pound & 4Jan71 - 10Jan03 & 8032 \\
\hline Canada & Canadian Dollar & 4Jan71 - 10Jan03 & 8038 \\
\hline China & Yuan & 2Jan81 - 10Jan03 & 5471 \\
\hline Denmark & Krone & 4Jan71 - 10Jan03 & 8031 \\
\hline Euro Area & False Euro & 4Jan93 - 10Jan03 & 2521 \\
\hline Finland & Markka & 4Jan71-31Dec98 & 6976 \\
\hline France & Franc & 4Jan71 - 31Dec98 & 7021 \\
\hline Germany & Deutsche Mark & 4Jan71 - 31Dec98 & 7021 \\
\hline Ireland & Pound & 4Jan71 - 31Dec98 & 7021 \\
\hline India & Rupee & 2Jan73 - 10Jan03 & 7525 \\
\hline Italy & Lira & 4Jan71 - 31Dec98 & 7020 \\
\hline Japan & Yen & 4Jan71 - 10Jan03 & 8026 \\
\hline Malaysia & Ringgit & 4Jan71 - 10Jan03 & 8010 \\
\hline Mexico & Peso & 8Nov93 - 10Jan03 & 2300 \\
\hline Netherlands & Guilder & 4Jan71 - 31Dec98 & 7021 \\
\hline New Zealand & New Zealand Dollar & 4Jan71 - 10Jan03 & 8016 \\
\hline Portugal & Escudo & 2Jan73 - 31Dec98 & 6518 \\
\hline Singapore & Singapore Dollar & 2Jan81 - 10Jan03 & 5531 \\
\hline South Africa & Rand & 4Jan71 - 10Jan03 & 8005 \\
\hline South Korea & Won & 13Apr81 - 10Jan03 & 5416 \\
\hline Spain & Peseta & 2Jan73 - 31Dec98 & 6521 \\
\hline Sri Lanka & Rupee & 2Jan73 - 10Jan03 & 7172 \\
\hline Sweden & Krona & 4Jan71 - 10Jan03 & 8031 \\
\hline Switzerland & Swiss Franc & 4Jan71 - 10Jan03 & 8032 \\
\hline Taiwan & Taiwan Dollar & 30 Oct $83-10 \mathrm{Jan} 03$ & 4548 \\
\hline Thailand & Baht & 2Jan81 - 10Jan03 & 5428 \\
\hline Venezuela & Bolivar & 2Jan95 - 10Jan03 & 2013 \\
\hline
\end{tabular}


Table 2

Parameters $\alpha$ and $\gamma$ for the currencies in Table 1.

\begin{tabular}{lll}
\hline Country & $\alpha$ & $\gamma$ \\
\hline Austrália & 1.41487 & .004656830 \\
Áustria & 1.90185 & .000010368 \\
Belgium & 1.56042 & .009849513 \\
Brazil & .89059 & .003707604 \\
Britain & 1.76454 & .000078676 \\
Canada & 2.04822 & .000005979 \\
China & 4.19286 & $2.5306 \mathrm{E}-11$ \\
Denmark & 1.39021 & .002288440 \\
Euro Area & 1.80054 & .000046794 \\
Finland & 1.75114 & .00040350 \\
France & 1.48668 & .001021003 \\
Germany & 1.54737 & .000330146 \\
Ireland & 1.61516 & .000150068 \\
India & 1.87979 & .000018721 \\
Italy & 1.27801 & .014513000 \\
Japan & 1.43542 & .011937000 \\
Malaysia & 2.78363 & .000000169 \\
Mexico & 1.60305 & .000923330 \\
Netherlands & 1.55999 & .00034082 \\
New Zealand & 1.87623 & .000011118 \\
Portugal & 1.33192 & .00514115 \\
Singapore & 1.81272 & .000027149 \\
South Africa & 3.46313 & $1.7417 \mathrm{E}-8$ \\
South Korea & .93298 & .015343000 \\
Spain & 1.28282 & .01962400 \\
Sri Lanka & 1.22370 & .000898138 \\
Sweden & 1.53611 & .000880928 \\
Switzerland & 1.68564 & .000209469 \\
Taiwan & 1.19228 & .003356487 \\
Thailand & 2.03006 & .000033537 \\
Venezuela & 4.13507 & $6.6404 \mathrm{E}-9$ \\
\hline
\end{tabular}


Table 3

Parameter estimates for selected currencies.

\begin{tabular}{lcccrccccc}
\hline Country & $\hat{\alpha}$ & $\hat{\gamma}$ & $\hat{\lambda}_{1}$ & \multicolumn{1}{c}{$\hat{\lambda}_{2}$} & \multicolumn{1}{c}{$\hat{\beta}_{1}$} & \multicolumn{1}{c}{$\hat{\beta}_{2}$} & $\hat{\vartheta}$ & $l_{c}$ & $l_{\max }$ \\
\hline Australia & 1.4753 & .00180229 & 8.3372 & 0.0000 & 2.2366 & 0.0000 & .00428 & .0000 & 0.27 \\
Brazil & 0.5960 & .00157227 & 3.3317 & 0.0000 & 1.0683 & 0.0000 & .00277 & .0000 & 0.27 \\
Britain & 1.5513 & .00520366 & 1.0086 & -3.7788 & -0.0276 & 2.4653 & .00000 & .0050 & 0.09 \\
Canada & 1.5599 & .00181284 & 2.8675 & -2.4219 & 0.8203 & 3.3156 & .00000 & .0035 & 0.04 \\
Denmark & 1.5117 & .02321810 & 4.7664 & -3.4188 & 0.8453 & 2.4294 & .00000 & .0350 & 1.10 \\
Euro Area & 1.8574 & .00039037 & 10.5374 & 0.0000 & 1.3456 & 0.0000 & -.00168 & .0015 & 0.07 \\
Hong Kong & 0.7600 & .00085047 & 4.0242 & -1.5663 & 0.8316 & 4.6757 & .00000 & .0000 & 0.70 \\
Japan & 1.4341 & .49351300 & 1.3605 & 0.0000 & 1.9274 & 0.0000 & .33850 & .7500 & 30.00 \\
Mexico & 1.4017 & .02356360 & 5.0413 & -1.5195 & 1.4748 & 2.7723 & .00000 & .0350 & 1.30 \\
New Zealand & 1.4061 & .00154540 & 5.0986 & -3.3148 & 0.7782 & 4.4101 & .00000 & .0000 & 0.22 \\
Norway & 1.5180 & .02001750 & 4.1884 & -2.0023 & 1.0801 & 1.3332 & .00000 & .0350 & 0.50 \\
Singapore & 1.4696 & .00270447 & 5.4180 & -0.7819 & 1.4317 & 1.4658 & .00000 & .0055 & 0.08 \\
South Korea & 0.6394 & .33273200 & 2.6583 & 0.0000 & 1.1408 & 0.0000 & .44520 & .0000 & 400.00 \\
Sweden & 1.4062 & .01853350 & 4.7843 & -2.9571 & 1.0297 & 2.3466 & .00000 & .0250 & 1.10 \\
Switzerland & 1.5984 & .00717332 & 4.3446 & -1.8323 & 1.1556 & 3.2261 & .00000 & .0125 & 0.17 \\
Taiwan & 1.0052 & .01627530 & 3.6706 & 0.0000 & 1.6571 & 0.00000 & .05930 & .0000 & 1.70 \\
\hline
\end{tabular}

Estimates $\hat{\alpha}$ and $\hat{\gamma}$ are obtained by the maximum likelihood method for $\Delta t=1$. Estimates $\hat{\lambda}_{1}, \hat{\lambda}_{2}, \hat{\lambda}_{3} \hat{\beta}_{1}$, $\hat{\beta}_{2}, \hat{\beta}_{3}$, and $\hat{\vartheta}$ are nonlinear least square estimates for the truncation parameters of the function using the SAS system (http://www.sas.com); and $l_{c}$ and $l_{\max }$ are empirically found from our data. Since $\hat{\lambda}_{3}$ and $\hat{\beta}_{3}=0$ for all cases, they have been omitted. 
Table 4

Single scaling and multiscaling.

\begin{tabular}{|c|c|c|c|}
\hline Country & Currency & Exponent $\xi$ & Exponent $\zeta$ \\
\hline Australia & Australian Dollar & Multiscaling (2) & Multiscaling (2) \\
\hline Austria & Shilling & Multiscaling (1.8) & Single Scaling \\
\hline Belgium & Belgian Franc & Single Scaling & Multiscaling (0.3) \\
\hline Brazil & Real & Single Scaling & Single Scaling \\
\hline Britain & Pound & Single Scaling & Single Scaling \\
\hline Canada & Canadian Dollar & Single Scaling & Single Scaling \\
\hline China & Yuan & Multiscaling (1) & Multiscaling (1) \\
\hline Denmark & Krone & Multiscaling (2) & Single Scaling \\
\hline Euro Area & False Euro & Multiscaling (2.2) & Single Scaling \\
\hline Finland & Markka & Multiscaling (2.1) & Single Scaling \\
\hline France & Franc & Multiscaling (2) & Single Scaling \\
\hline Germany & Deutsche Mark & Multiscaling (2) & Single Scaling \\
\hline Ireland & Pound & Multiscaling (2) & Single Scaling \\
\hline India & Rupee & Multiscaling (2) & Multiscaling (1.4) \\
\hline Italy & Lira & Multiscaling (2.5) & Multiscaling (0.1) \\
\hline Japan & Yen & Multiscaling (2) & Multiscaling (0.25) \\
\hline Malaysia & Ringgit & Multiscaling (1.8) & Multiscaling (2) \\
\hline Mexico & Peso & Multiscaling (2) & Multiscaling (1.5) \\
\hline Netherlands & Guilder & Multiscaling (2.5) & Single Scaling \\
\hline New Zealand & New Zealand Dollar & Multiscaling (1.5) & Single Scaling \\
\hline Portugal & Escudo & Multiscaling (2.5) & Multiscaling (0.2) \\
\hline Singapore & Singapore Dollar & Multiscaling (2) & Single Scaling \\
\hline South Africa & Rand & Multiscaling (1) & Multiscaling (2) \\
\hline South Korea & Won & Multiscaling (1.5) & Multiscaling (2) \\
\hline Spain & Peseta & Multiscaling (2) & Multiscaling $(\sim 0)$ \\
\hline Sri Lanka & Rupee & Multiscaling $(\sim 0)$ & Multiscaling $(\sim 0)$ \\
\hline Sweden & Krona & Multiscaling (2) & Multiscaling (3) \\
\hline Switzerland & Swiss Franc & Multiscaling (2.5) & Single Scaling \\
\hline Taiwan & Taiwan Dollar & Multiscaling (1.5) & Multiscaling (0.5) \\
\hline Thailand & Baht & Multiscaling $(\sim 0)$ & Multiscaling (0.5) \\
\hline Venezuela & Bolivar & Multiscaling (1) & Multiscaling $(\sim 0)$ \\
\hline
\end{tabular}

An approximate linear behavior for all $K\left(\right.$ all $\left.\kappa(\alpha)=|K|^{\alpha}\right)$ gives evidence of mere single scaling. In turn, a linear behavior for initial values of $K<\alpha_{0}\left(\kappa(\alpha)<\alpha_{0}\right)$ followed by a nonlinear pattern after $K>\alpha_{0}(\kappa(\alpha)>$ $\alpha_{\mathrm{o}}$ ) tracks the presence of multiscaling. 

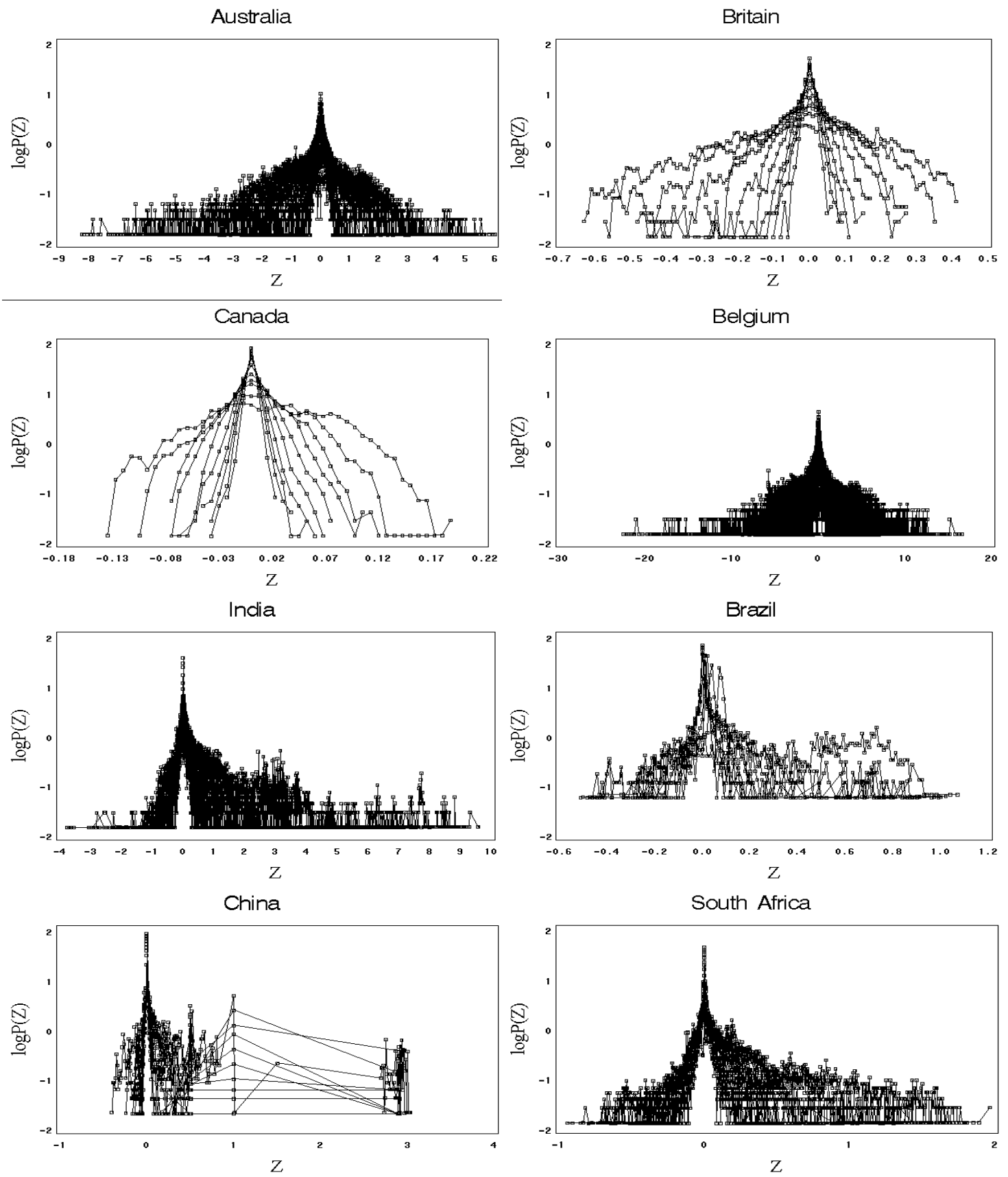

Fig. 1. Probability density functions of the currency returns of Australia, Britain, Canada, Belgium, India, Brazil, China, and South Africa observed at time intervals $\Delta t$, which range from 1 to 240 trading days. As $\Delta t$ is increased, a spreading of the probability distribution characteristic of any random walk is observed. 

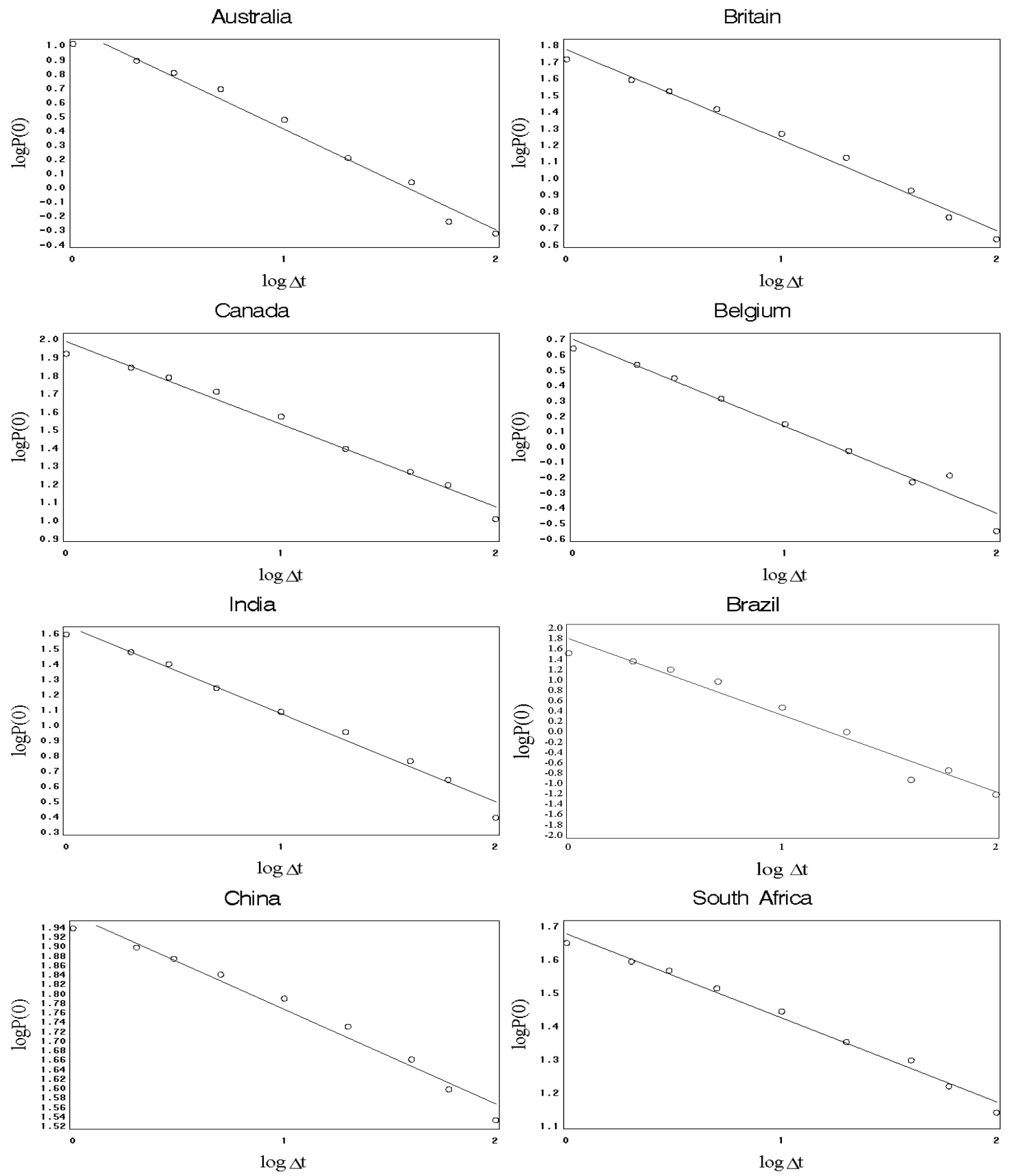

Fig 2. Log-log plot of the probability of return to the origin $P(0)$ against the time lag $\Delta t$ for the currency returns of Australia, Britain, Canada, Belgium, India, Brazil, China, and South Africa. Power laws emerge within the time window of $1 \leq \Delta t \leq 100$. This non-Gaussian scaling is consistent with the presence of a TLF. 

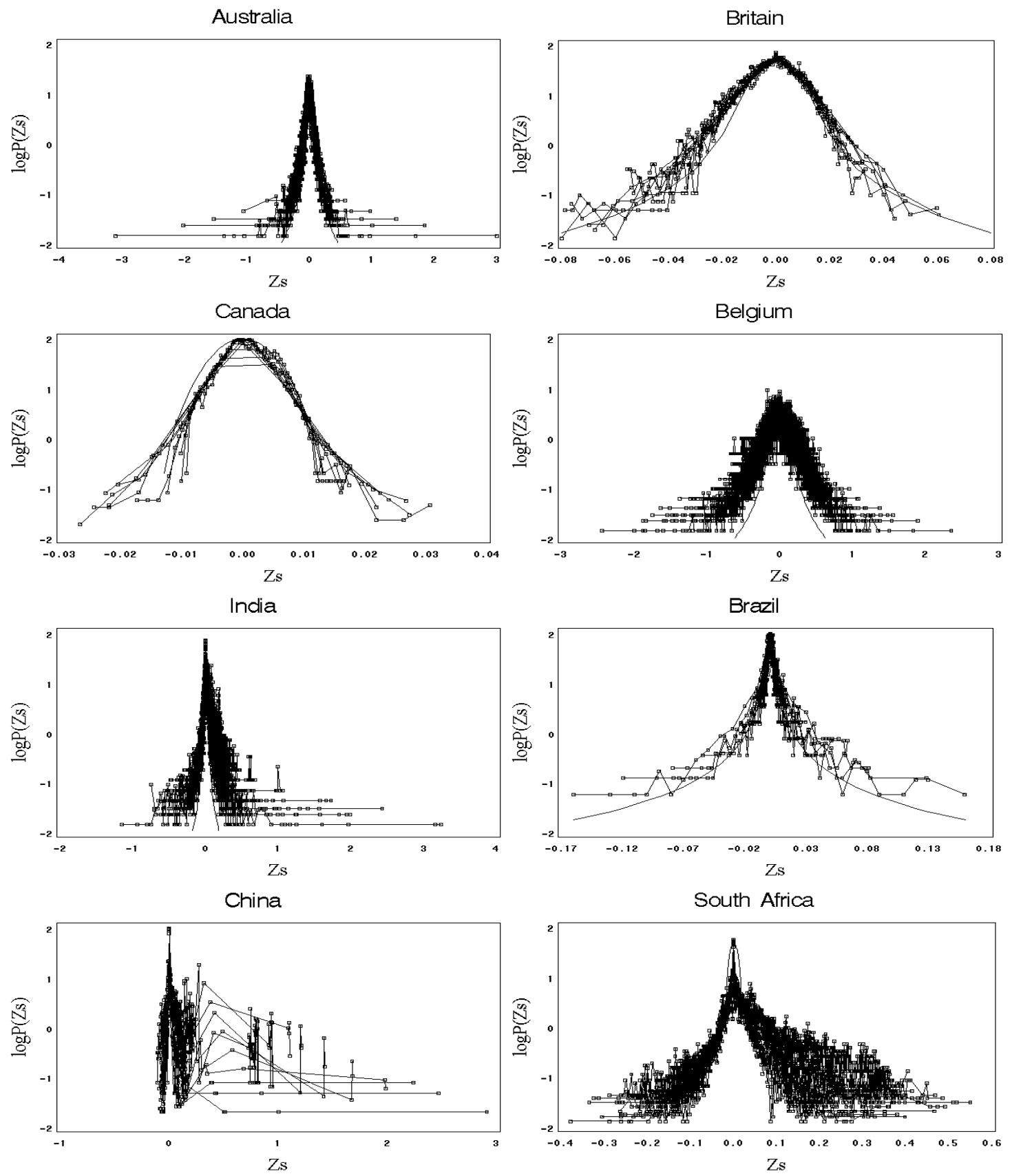

Fig. 3. The same PDFs as in Fig. 1, but now plotted in scaled units $P(Z)$. Given the scaling index $\alpha$ for a given currency, all the data is made to collapse onto a $\Delta t=1$ distribution. 

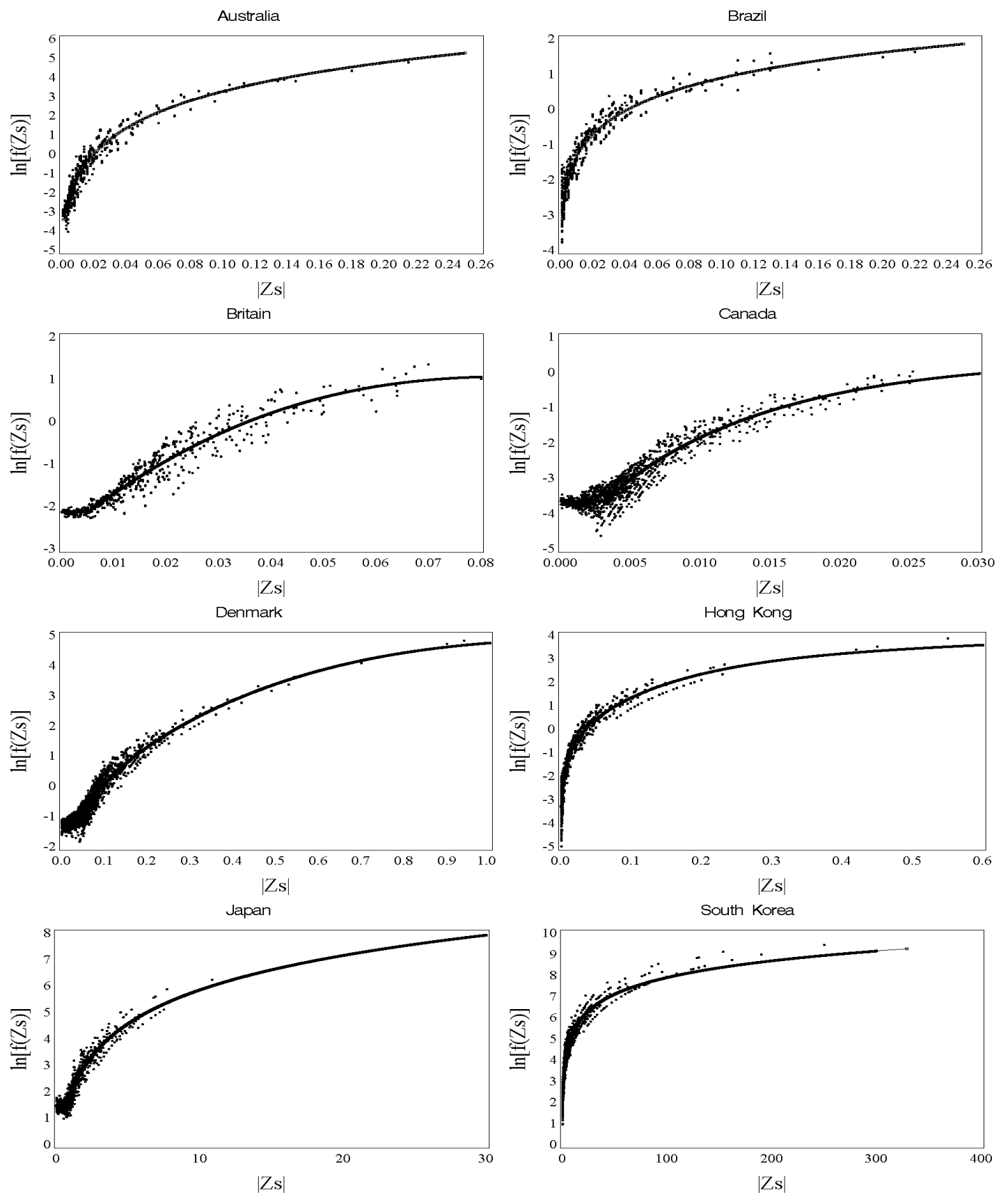

Fig. 4. Log of differences showing how the observed log PDFs of currency returns deviate from the original $\log$ Lévy process. The continuous lines are the fittings using the variance and $z_{s}=\Delta t^{-1 / \hat{\alpha}} z_{\Delta t}$. 

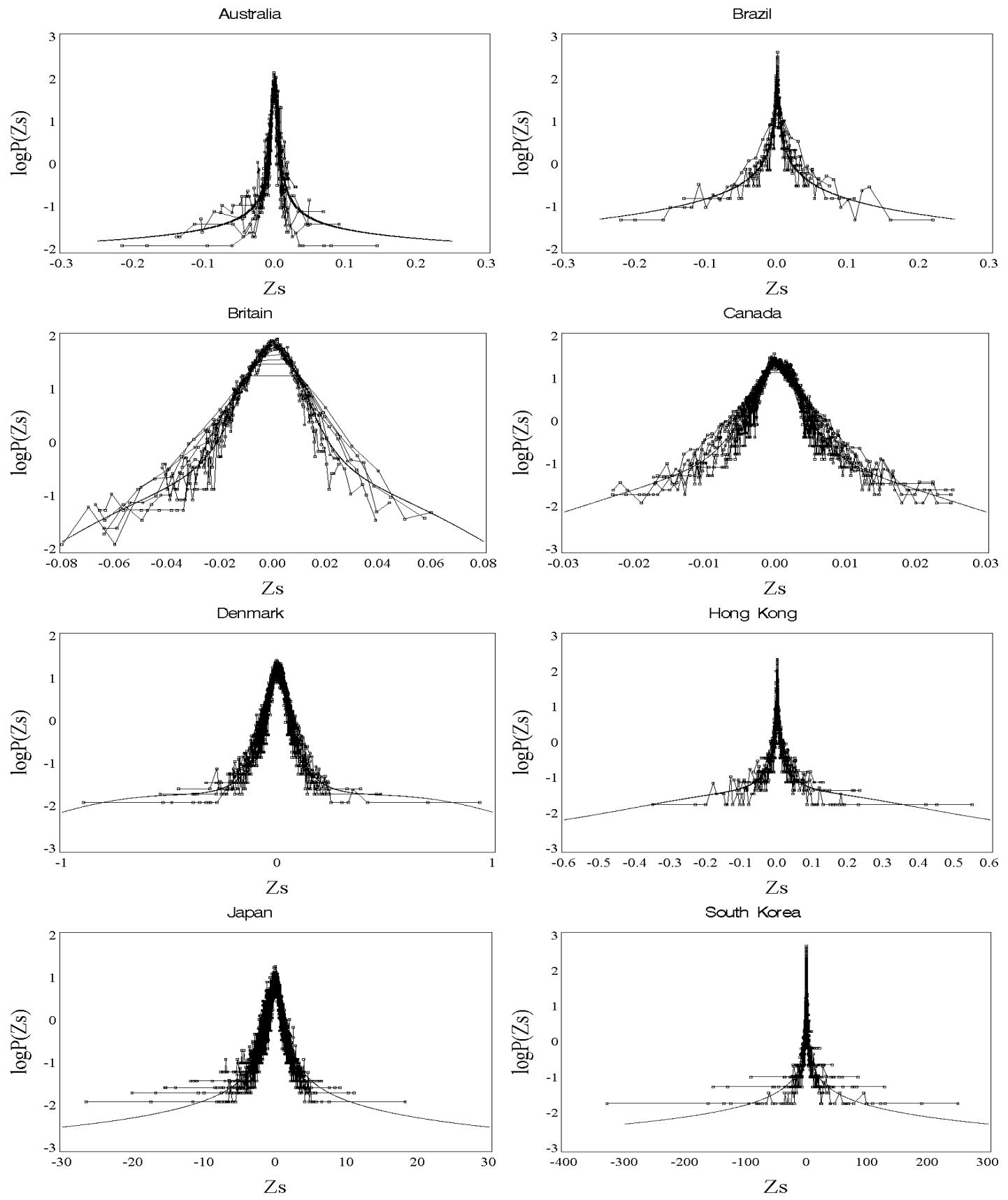

Fig. 5. The same PDFs as in Fig. 1 but now plotted in scaled units $P\left(Z_{s}\right)$, where $z_{s}=\Delta t^{-1 / \hat{\alpha}} z_{\Delta t}$. Given the scaling index $\alpha$ for a currency, the data are made to collapse onto a $\Delta t=1$ distribution. The curves are our suggested exponentially damped Lévy flights estimated from the data. 

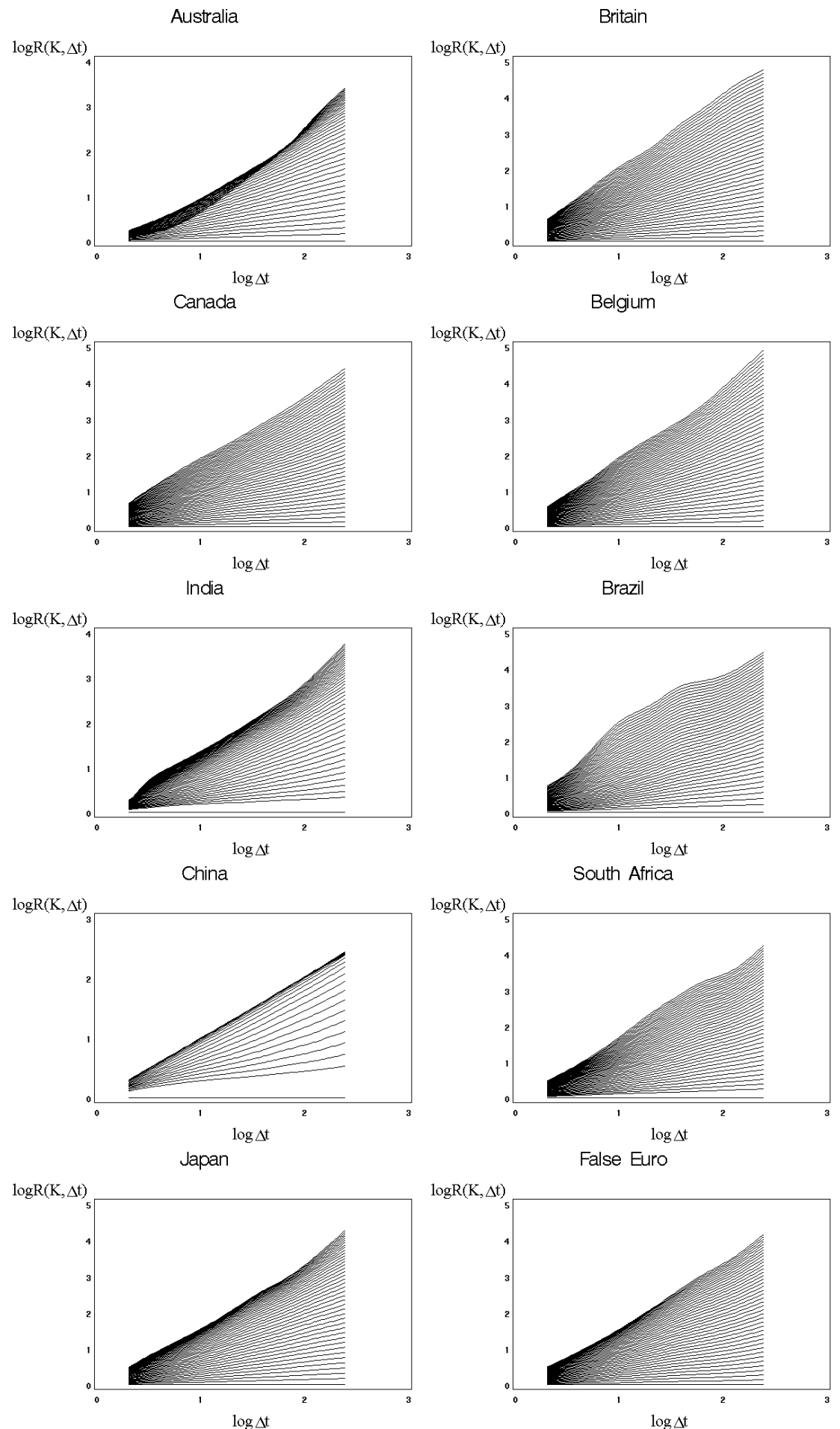

Fig.6. Estimated ratios $R(K, \Delta t)$ of selected exchange rates for $K=0.0-3.0$ at intervals of 0.2 . For each plot, the bottom line corresponds to $K=0.0$, and the top one to $K=3.0$. 

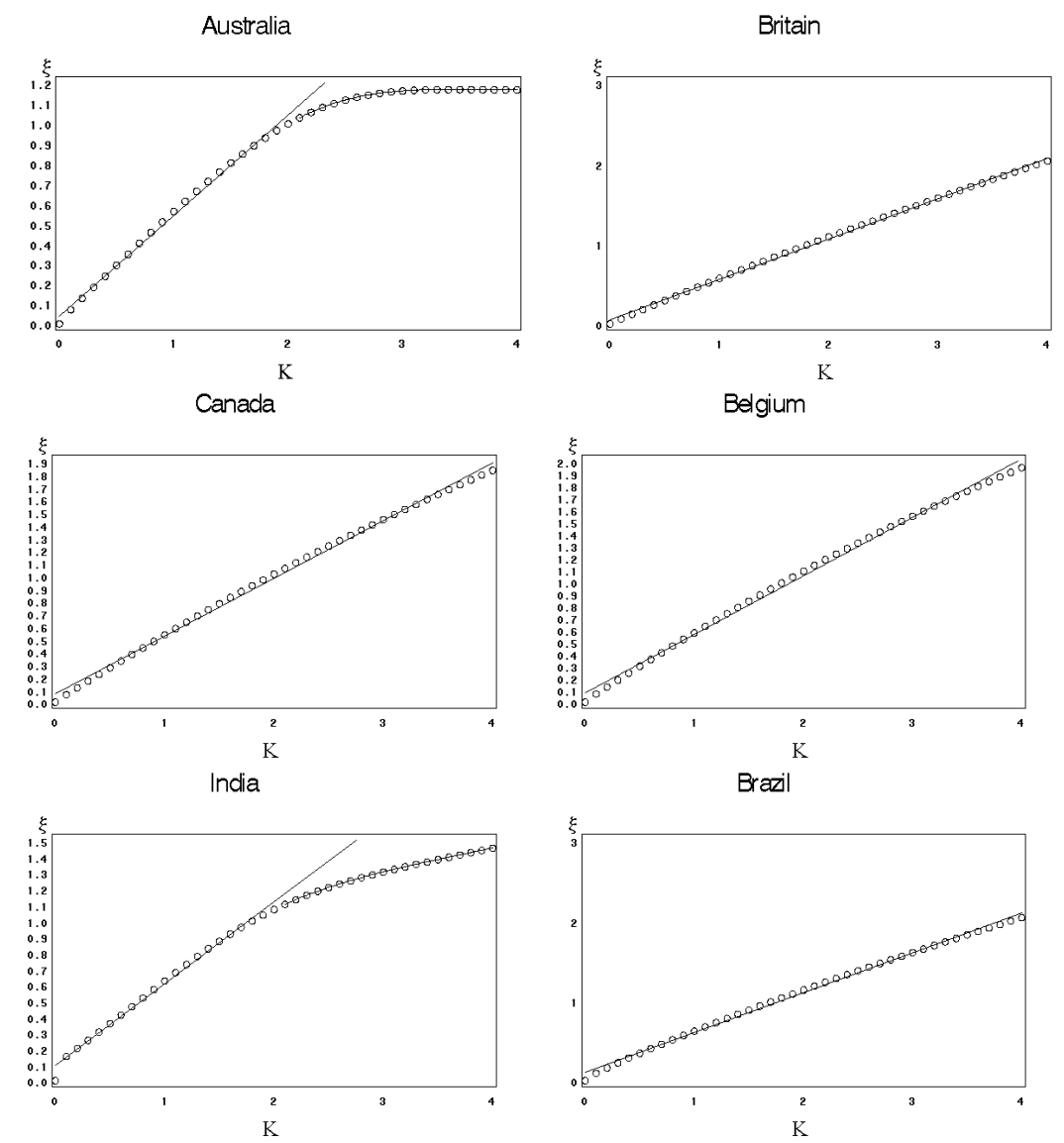

China

South Africa
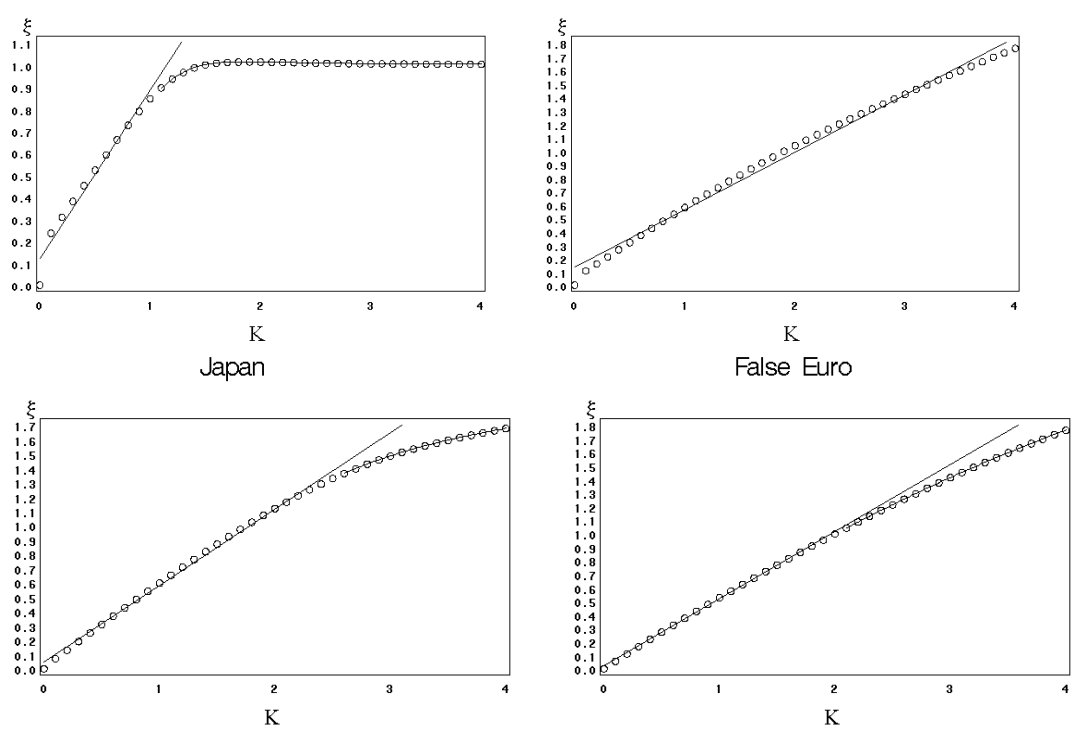

Fig. 7. Estimated multiscaling exponents $\xi$ for selected exchange rates. An approximate linear behavior for all $K$ gives a piece of evidence of mere single scaling. A linear behavior for initial values of $K<\alpha$ followed by a nonlinear pattern after $K>\alpha$ tracks the presence of multiscaling. 

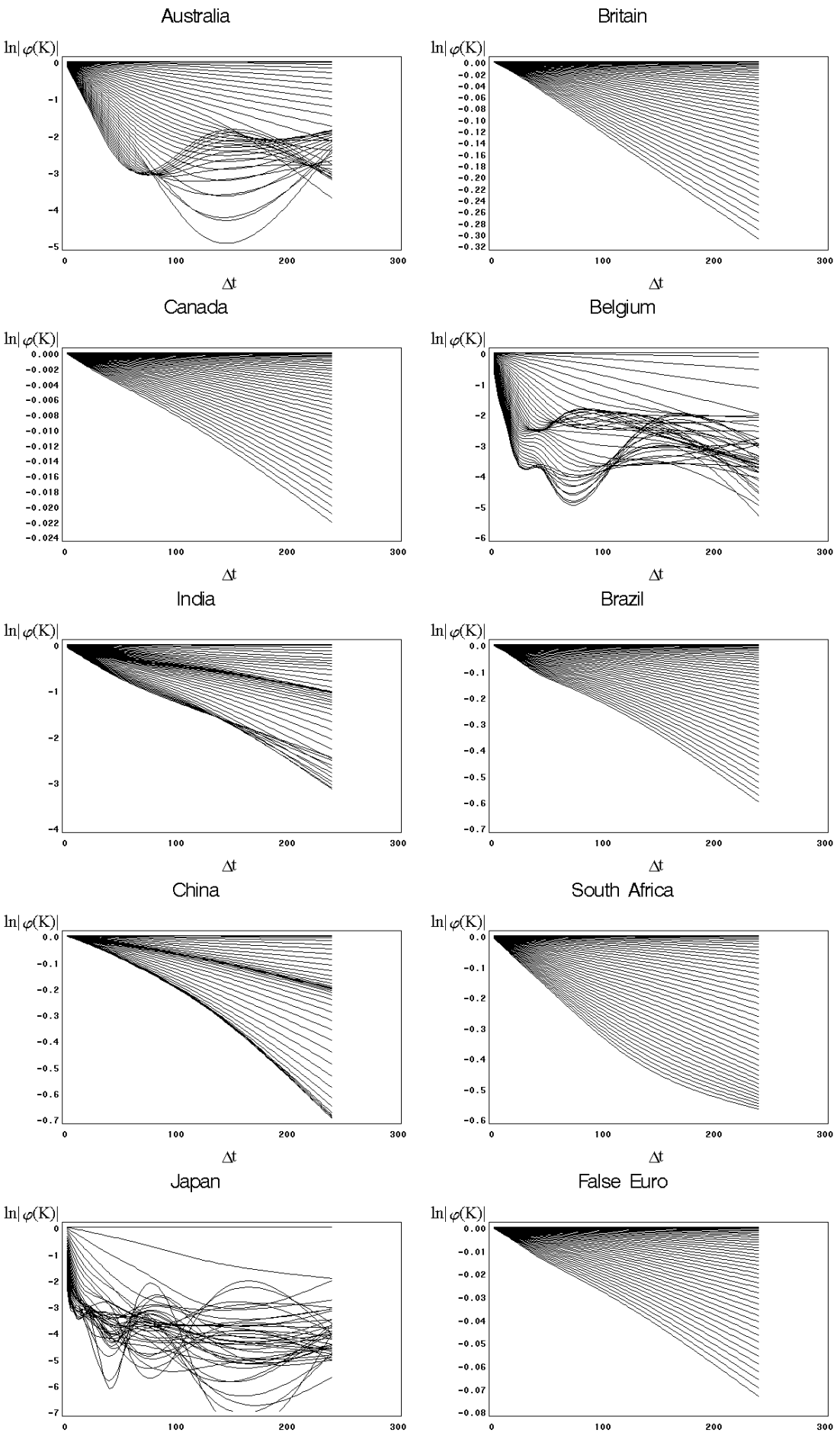

Fig. 8. Estimated ratios $\ln \left\|\varphi_{L}(K)\right\|$ for selected exchange rates for $K=0.0-3.0$ at intervals of 0.2 . For each plot, the upper line corresponds to $K=0.0$, and the bottom one to $K=3.0$. 

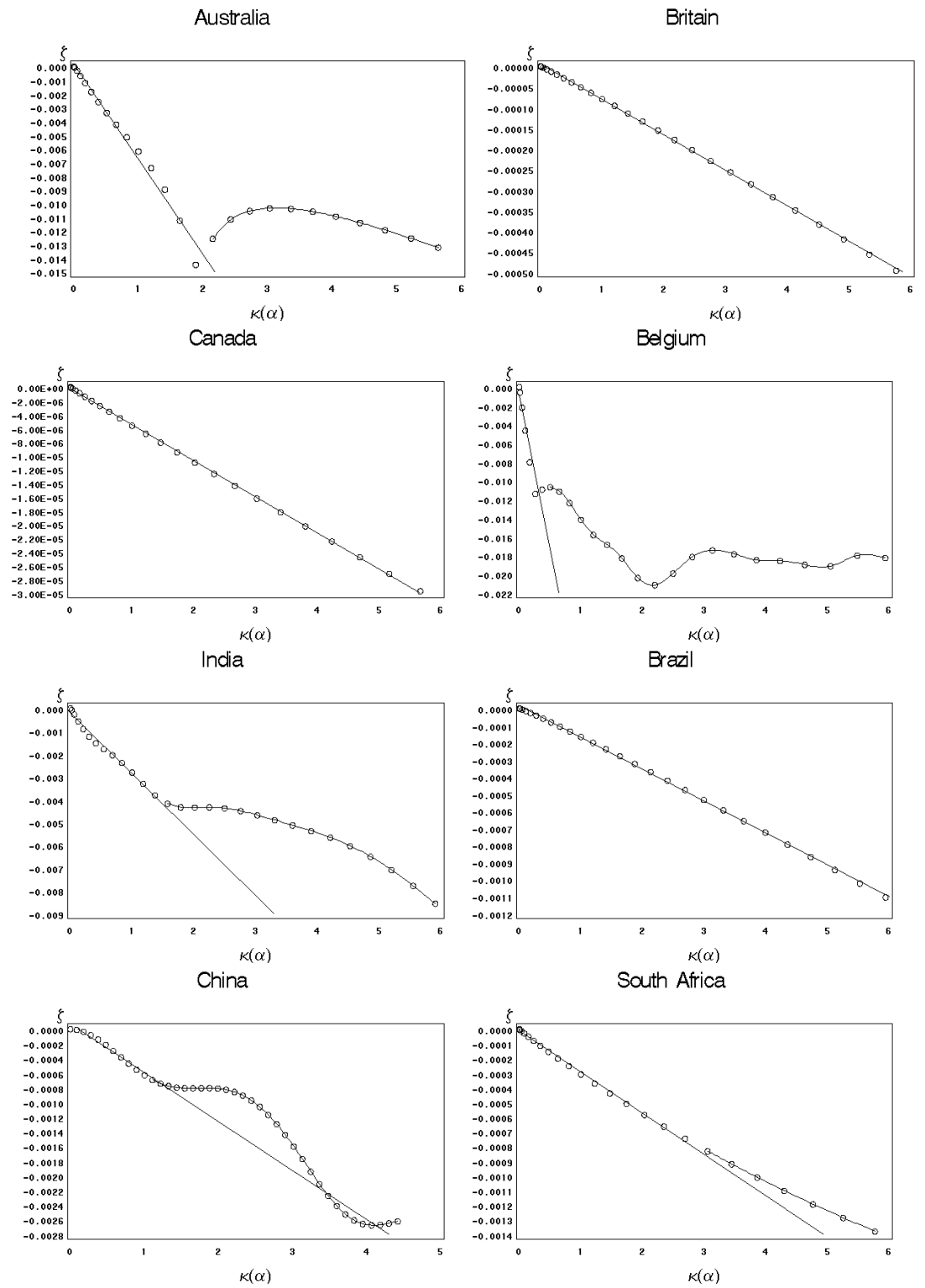

South Africa
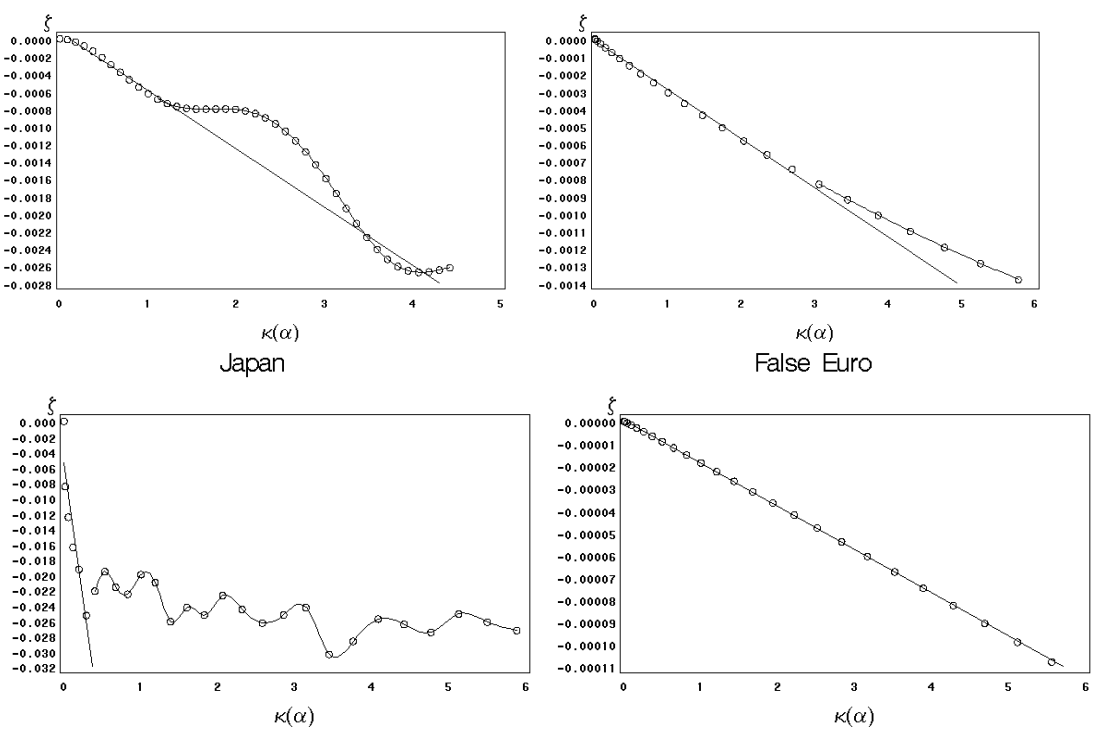

Fig. 9. Estimated multiscaling exponents $\zeta$ for selected exchange rates. An approximate linear behavior for all $\kappa(\alpha)=|K|^{\alpha}$ indicates mere single scaling. A linear behavior for initial values of $\kappa(\alpha)<\alpha_{0}$ followed by a nonlinear pattern after $\kappa(\alpha)>\alpha_{0}$ captures the presence of multiscaling. 


\section{References}

[1] P.R. Krugman, The case for stabilizing exchange rates, Oxford Review of Economic Policy 5 (1989) 6172.

[2] R.J. Shiller, Stock prices and social dynamics, The Brookings Papers on Economic Activity 2 (1984) 457510.

[3] J.M. Keynes, The General Theory of Employment, Interest, and Money, Macmillan, London, 1936.

[4] R. Skidelsky, Skidelsky on Keynes, The Economist, 25 November (2000) 83-85.

[5] J.R. Hicks, Mr Keynes and the classics: a suggested interpretation, Econometrica 5 (1937) 147-159.

[6] R.J. Shiller, Speculative prices and popular models, Journal of Economic Perspectives 4 (1990) 55-65.

[7] W.B. Arthur, Inductive reasoning and bounded rationality, American Economic Review 84 (1994) 406411 .

[8] W.B. Arthur, Complexity and the economy, Science 284 (1999) 107-109.

[9] W.B. Arthur, J.H. Holland, B. LeBaron, R. Palmer, P. Tayler, Asset pricing under endogenous expectations in an artificial stock market, in: W.B. Arthur, S.N. Durlauf, D.A. Lane (Eds.), The Economy as an Evolving Complex System II, Addison-Wesley, Reading, 1997.

[10] O.J. Blanchard, Speculative bubbles, crashes and rational expectations, Economics Letters 3 (1979) 387389.

[11] T. Lux, D. Sornette, On rational bubbles and fat tails, Journal of Money, Credit, and Banking 34 (2002) 589-610.

[12] S. Wolfram, A New Kind of Science, Wolfram Media Inc., Champaign, 2002.

[13] P.R. Krugman, The Self-Organizing Economy, Blackwell, Oxford, 1996.

[14] R. Dornbusch, Expectations and exchange rate dynamics, Journal of Political Economy 84 (1976) 11611176.

[15] M. Obstfeld, K. Rogoff, Exchange rate dynamics redux, Journal of Political Economy 103 (1995) 624660 .

[16] M. Obstfeld, K. Rogoff, Foundations of International Macroeconomics, The MIT Press, Cambridge, 1996.

[17] M. Eichenbaum, C.L. Evans, Some empirical evidence on the effects of shocks to monetary policy on exchange rates, The Quarterly Journal of Economics 110 (1995) 975-1009.

[18] R.P. Flood, Explanations of exchange rate volatility and other empirical regularities in some popular models of the foreign exchange market, Carnegie-Rochester Conference Series on Public Policy 15 (1981) 219-249.

[19] M.P. Taylor, The economics of exchange rates, Journal of Economic Literature 33 (1995) 13-47.

[20] P. Isard, Exchange Rate Economics, Cambridge University Press, Cambridge, 1995. 
[21] A.C. Stockman, The equilibrium approach to exchange rates, Federal Reserve Bank of Richmond Economic Review 73 (1987) 12-30.

[22] K.A. Froot, K. Rogoff, Perspectives on PPP and long-run real exchange rates, in: G. Grossman, K. Rogoff (Eds.), Handbook of International Economics, Volume 3, North-Holland, Amsterdam, 1995, pp. 1647 1688.

[23] J.D. Sachs, The current account and macroeconomic adjustment in the 1970s, Brookings Papers on Economic Activity 1 (1981) 201-282.

[24] M. Obstfeld, Aggregate spending and the terms of trade: is there a Laursen-Metzler effect?, The Quarterly Journal of Economics 97 (1982) 251-270.

[25] J.A. Frankel, A. Razin, Fiscal Policies and Growth in the World Economy, Third Edition, The MIT Press, Cambridge, 1996.

[26] R.A. Meese, K. Rogoff, Empirical exchange rate models of the seventies: do they fit out of sample? Journal of International Economics 14 (1983a) 3-24.

[27] R.A. Meese, K. Rogoff, The out-of-sample failure of empirical exchange rate models: sampling error or misspecifications?, in: J.A. Frenkel (Ed.), Exchange Rates and International Economics. The University of Chicago Press, Chicago, 1983b, pp. 67-105.

[28] R.A. Meese, K. Rogoff, Was it real? The exchange rate-interest differential relation over the modern floating-rate period, Journal of Finance 43 (1988) 933-948.

[29] R.A. Meese, K.J. Singleton, On unit roots and the empirical modelling of exchange rates, Journal of Finance 37 (1982) 1029-1035.

[30] D. Corbae, S. Ouliaris, Robust test for unit roots in the foreign exchange rate market, Economics Letters 22 (1986) 375-380.

[31] R.T. Baillie, T. Bollerslev, Common stochastic trends in a system of exchange rates, Journal of Finance 44 (1989) 167-181.

[32] R.T. Baillie, P.C. McMahon, The Foreign Exchange Market: Theory and Econometric Evidence, Cambridge University Press, Cambridge, 1989.

[33] K.G. Koedijk, P. Schotman, How to beat the random walk: an empirical model of real exchange rates, Journal of International Economics 29 (1990) 311-332.

[34] N.C. Mark, Exchange rates and fundamentals: evidence on long-horizon predictability, The American Economic Review 85 (1995) 201-218.

[35] M.D. Chinn, R.A. Meese, Banking on currency forecasts: how predictable is change in money?, Journal of International Economics 38 (1995) 161-178.

[36] P. De Grauwe, H. Dewachter Chaos in the Dornbusch model of the exchange rate, Kredit und Kapital 25 (1992) 26-54.

[37] P. De Grauwe, H. Dewachter, M. Embrechts, Exchange Rate Theory: Chaotic Models of Foreign Exchange Markets, Blackwell, Oxford, 1993.

[38] S. Da Silva, The role of foreign exchange intervention in a chaotic Dornbusch model, Kredit und Kapital 33 (2000) 309-345. 
[39] R. Dornbusch, Exchange rate economics: 1986, The Economic Journal 97 (1987) 1-18.

[40] R. Dornbusch, J.A. Frankel, The flexible exchange rate system: experience and alternatives, in: S. Borner (Ed.), International Finance and Trade, Macmillan, London, 1988.

[41] M. Baxter, A. C. Stockman, Business cycles and the exchange rate regime: some international evidence, Journal of Monetary Economics 23(3) (1989) 377-400.

[42] R.C. Marston, Real and nominal exchange rate variability, Empirica 16 (1989) 147-160.

[43] J.A. Frankel, K.A. Froot, Chartists, fundamentalists and the demand for dollars, in: A.S. Courakis, M.P. Taylor (Eds.), Private Behaviour and Government Policy in Interdependent Economies, Oxford University Press, Oxford, 1990, pp. 73-126.

[44] R.P. Flood, A.K. Rose, Fixing exchange rates: a virtual quest for fundamentals, CEPR Discussion Papers No. 838 (1993).

[45] M.D. Flood, Microstructure theory and the foreign exchange market, Federal Reserve Bank of St. Louis Review 73 (1991) 52-70.

[46] J.A. Frankel, G. Galli, A. Giovannini, The Microstructure of Foreign Exchange Markets, The University of Chicago Press, Chicago, 1995.

[47] C.A.E. Goodhart, News and the foreign exchange market, LSE Financial Markets Group Discussion Papers No. 71 (1989).

[48] J.A. Frankel, A.K. Rose, Empirical research on nominal exchange rates, in: G. Grossman, K. Rogoff (Eds.), Handbook of International Economics, Volume 3, North-Holland, Amsterdam, 1995, pp. 1689-1729.

[49] A.C. Stockman, A theory of exchange rate determination, Journal of Political Economy 88 (1980) 673698.

[50] R.E. Lucas, Interest rates and currency prices in a two-country world, Journal of Monetary Economics 10 (1982) 335-359.

[51] L.E.O. Svensson, Currency prices, terms of trade, and interest rates: a general equilibrium asset-pricing, cash-in-advance approach, Journal of International Economics 18 (1985) 17-41.

[52] V. Grilli, N. Roubini, Liquidity and exchange rates, Journal of International Economics 32 (1992) 339352 .

[53] S. Da Silva, Classroom guide to the equilibrium exchange rate model, Economic Issues 7 (2002) 1-10.

[54] F. Van Der Ploeg, The Handbook of International Macroeconomics, Blackwell, Oxford, 1994.

[55] P.R. Lane, The new open economy macroeconomics: a survey, Journal of International Economics 54 (2001) 235-266.

[56] L. Sarno, Toward a new paradigm in open economy modeling: where do we stand?, Federal Reserve Bank of St. Louis Review, May/June (2001) 21-36.

[57] S. Da Silva, Chaotic exchange rate dynamics redux, Open Economies Review 12 (2001) 281-304.

[58] H.E. Stanley, L.A.N. Amaral, X. Gabaix, P. Gopikrishnan, V. Plerou, Similarities and differences between physics and economics, Physica A 299 (2001) 1-15. 
[59] L. Bachelier, Theorie de la speculation ( $\mathrm{PhD}$ thesis in mathematics), Annales Scientifiques de 1'Ecole Normale Superieure III-7 (1900) 21-86.

[60] P. Gopikrishnan, M. Meyer, L.A.N. Amaral, H.E. Stanley, Inverse cubic law for the distributions of stock price variations, The European Physical Journal B 3 (1997) 139-140.

[61] Y. Liu, P. Gopikrishnan, P. Cizeau, M. Meyer, C.K. Peng, H.E. Stanley, Statistical properties of the volatility of price fluctuations, Physical Review E 60 (1999) 1390-1400.

[62] B.B. Mandelbrot, The variation of certain speculative prices, J. Business 36 (1963) 394-419.

[63] D. Dugué, Oeuvres de Paul Lévy, Volume III, Eléments Aléatoires, Gauthiers-Villars, Paris, 1976.

[64] B. Mandelbrot, The Fractal Geometry of Nature, Freeman, San Francisco, 1982.

[65] A. Lo, A.C. MacKinlay, Stock market prices do not follow random walks: evidence from a simple specification test, Review of Financial Studies 1 (1988) 41-66.

[66] P. Cootner, The Random Character of Stock Market Prices, The MIT Press, Cambridge, 1964.

[67] R.N. Mantegna, H.E. Stanley, Stochastic process with ultraslow convergence to a Gaussian: the truncated Lévy flight, Phys. Rev. Lett. 73 (1994) 2946-2949.

[68] R.N. Mantegna, H.E. Stanley, Scaling behavior in the dynamics of an economic index, Nature 376 (1995) 46-49.

[69] L.C. Miranda, R. Riera, Truncated Lévy walks and an emerging market economic index, Physica A 297 (2001) 509-520.

[70] I. Gleria, R. Matsushita, S. Da Silva, Scaling power laws in the Sao Paulo Stock Exchange, Economics Bulletin 7 (2002) 1-12.

[71] J.A. Skjeltorp, Scaling in the Norwegian stock market, Physica 283 (2001) 486-525.

[72] A. Figueiredo, I. Gleria, R. Matsushita, S. Da Silva, Autocorrelation as a source of truncated Lévy flights in foreign exchange rates, Physica A 323 (2003) 601-625.

[73] U. Müller, M.M. Dacorogna, R.B. Olsen, O.V. Pictet, M. Schwarz, C. Morgenegg, Statistical study of foreign exchange rates, empirical evidence of a price change scaling law, and intraday analysis, Journal of Banking \& Finance 14 (1990) 1189-1208.

[74] R. Mantegna, H.E. Stanley, An Introduction to Econophysics, Correlations and Complexity in Finance, Cambridge University Press, Cambridge, 2000.

[75] P. Lévy, Theorie de L’Addition des Variables Aleatoires, Gauthier-Villars, Paris, 1937.

[76] G. M. Zaslavsky, Chaos, fractional kinetics, and anomalous transport, Phys. Rep. 371 (2002) 461-580.

[77] I. Koponen, Analytic approach to the problem of convergence of truncated Lévy flights towards the Gaussian stochastic process, Phys. Rev. E. 52 (1995) 1197-1199.

[78] H. Nakao, Multi-scaling properties of truncated Lévy flights, Phys. Lett. A 266 (2000) 282-289.

[79] H.M. Gupta, J.R. Campanha, The gradually truncated Lévy flight for systems with power-law 
distributions, Physica A 268 (1999) 231-239.

[80] H.M. Gupta, J.R. Campanha, The gradually truncated Lévy flight: stochastic process for complex systems, Physica A 275 (2000) 531-543.

[81] R. Matsushita, P. Rathie, S. Da Silva, Exponentially damped Lévy flights, Physica A 326 (2003) 544555.

[82] B. Dubrulle, J.P. Laval, Truncated Lévy laws and 2D turbulence, Eur. Phys. J. B 4 (1998) 143-146.

[83] N. Vandewalle, M. Ausloos, Multi-affine analysis of typical currency exchange rates, Eur. Phys. J. B 4 (1998) 257-261.

[84] K. Ivanova, M. Ausloos, Low q-moment multifractal analysis of gold price, Dow-Jones industrial average and BGL-USD exchange rate, Eur. Phys. J. B 8 (1999) 665-669.

[85] F. Schmitt, D. Schertzer, S. Lovejoy, Multifractal analysis of foreign exchange data, Appl. Stoch. Model Data Anal. 15 (1999) 29-53.

[86] R. Gencay, F. Selcuk, B. Whitcher, Scaling properties of foreign exchange volatility, Physica A 289 (2001) 249-266.

[87] Z. Xu, R. Gencay, Scaling, self-similarity and multifractality in FX markets, Physica A 323 (2003) 578590.

[88] A. Bershadskii, Self-averaging phenomenon and multiscaling in Hong Kong stock market, Physica A 317 (2003) 591-596.

[89] M. Ausloos, K. Ivanova, Introducing false EUR and false EUR exchange rates, Physica A 286 (2000) 353-366.

[90] D. Sornette, K. Ide, The Kalman-Lévy filter, Physica D 151 (2001) 142-174.

[91] J.P. Nolan, Maximum likelihood estimation and diagnostics for stable distributions, American University, Washington D.C. (1999). Available at http://academic2.american.edu/ jpnolan/.

[92] R. Matsushita, I. Gleria, A. Figueiredo, P. Rathie, S. Da Silva, Exponentially damped Lévy flights, multiscaling, and exchange rates, Physica A, forthcoming. 